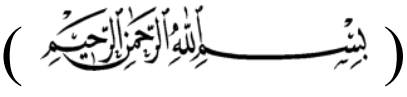

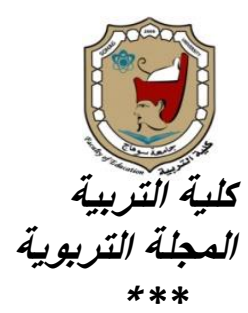

أثر استخدام التعلم المنظم ذاتيَا في تنمية مهارات التذوق الأدبي لدى طلاب الصف الأول الثانوي.

أ. د/ أحمد محمد علي رشـــــــــوار أستاذ المناهج وطرق تدريس اللغة العربية والدراسات الإسلامية- كلية التربية-جامعة أسيوط

\title{
إعداد
}

أ / حسام الدين مصطفى البدري محمد

معلم اللغة العربية والتربية الدينية الإسلامية الإية البرية

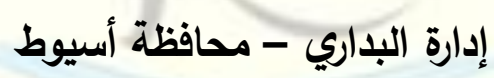

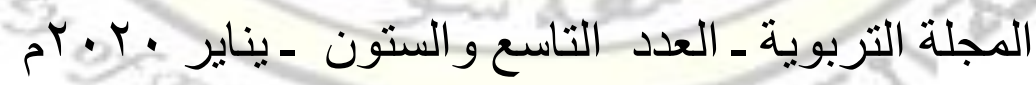

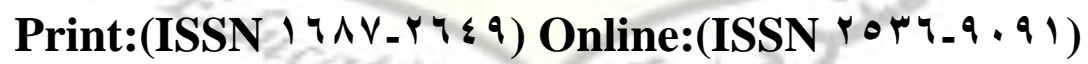




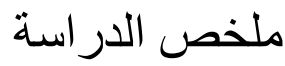

التذوق الأدبي هو الغاية من دراسة وتحليل النصوص الأدبية، ويمكن أن يتحقق ذلك للمتعلم من خلال تذوق النواحي البلاغية والصور البيانية في النص الأدبي التي تمكنه من فهم النص فهماً جيداً ومعرفة مقصود الثاعر من الأبيات؛ لذلك فإن مهارات التذوق الأدبي يتوصل إليها المتعلم من خلال البلاغة والتحليل البلاغي للنصوص الأدبية. والتعلم المنظم ذاتياً يساعد المتعلم في زيادة التحصيل الدراسي وزيادة الدافعية وتنمية

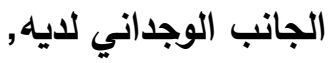
وكل ما سبق يساعد المتعلم في تنمية مهارات التذوق الأدبي لايه. هإن وقد نبعت مشكلة الدراسة من خلال الثواهد التالية: 1-ملاحظة الباحث من خلال عمله معلمًا للغة العربية والتربية الدينية الإسلامية لطلاب المرحلة الثانوية. r ب-الاطلاع على نتائج وتوصيات الدراسات السابقة. *ومن ثمّ حاولت الاراسة الحالية الإجابة عن الأسئلة الآتية: 1-ما مهارات التذوق الأدبي المناسبة لطلاب الصف الأول الثانوي؟ r-ما البرنامج القائم على التعلم المنظم ذاتيًا لتنمية مهارات التذوق الأدبي لاى طلاب الصف الصف الأول الثانوي؟ ץ-ما فاعلية برنامج قائم على التعلم المنظم ذاتيا في تنمية مهارات التذوق الأدبي لاى طلاب الصف الأول الثانوي؟

$$
\text { وقد توصلت الاراسة إلى مجموعة من النتائج تمثلت في: }
$$

ا-قائمة بمهارات التذوق الأدبي المناسبة لطلاب الصف الأول الثانوي, وقد اشتملت القائمة في صورتها النهائية على أربعة جوانب رئيسة, هي: (الجانب الفكري- الجانب البيانيالجانب الوجداني- الجانب الاجتماعي)، وتفرعت عنها ( • ب) مهارة فرعية.

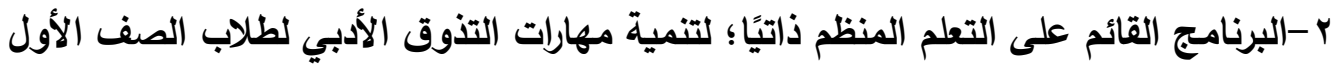
الثانوي, وقد تطلب البرنامج إعداد كتاب الطالب, ودليل المعلم لتدريس البرنامج. r-فاعلية البرنامج القائم على التعلم المنظم ذاتيًا في تنمية مهارات التذوق الأدبي المستهدفة بالدراسة لاى طلاب الصف الأول الثانوي, وتبين ذلك من خلال حساب الفروق بين 
أثن استخدام التعلم المنظم ذاتيًا في تنمية مهارات التذوق الأدبي.

المتوسطات لنتائج اختبار مهارات التذوق الأدبي ككل, وعلى المهارات الرئيسة له كل على حدة في التطبيقين القبلي والبعدي, وجاء الفرق دالاً إحصائيًا عند مستوى (1 (...) لصالح التطبيق البعدي في اختبار التذوق الأدبي, وكان حجم أثر البرنامج كبيرًا. 
Using the Self-Organized Learning For Developing Literary Appreciation Skills of the First Year of Secondary Students. The fifth chapter:

In this respect, literary appreciation is the ultimate aim of studying and analyzing literary texts, and learners can achieve this through appreciating the rhetorical aspects and figures of speech in the literary text which can help him/her to better understand the text and recognize the poet's intended meaning out of lines of verse. Therefore, the learner can achieve literary appreciation skills through rhetoric and rhetorical analysis of literary texts.

Self-regulated learning, in this regard, helps increase the learner's academic achievement, motivation, and emotional aspect. All the above helps the learner acquire rhetorical concepts and develop their literary appreciatio Thus, the problem of this study stemmed from the following instances:

1-the researcher's observation during working as a teacher of Arabic language and Islamic studies for secondary students

$r$-reviewing the results and recommendations of previous studies

\# the current study aimed to answer the following questions:

1- What literary appreciation skills are suitable for first year secondary stage students?

$r$ - What is the scenario of the self-regulated-learning-based program for developing literary appreciation skills of first year secondary stage students?

r- How effective of the self-regulated-learning-based program in developing literary appreciation skills of first year secondary stage students?

*The study concluded with some results as follows:

1 - The study produced a list of literary appreciation skills suitable for first year secondary students, including in its final form the following four sections: the cognitive, the rhetorical, the emotional, and the social, of which $r \cdot$ sub-skills branched

$r$ - It also produced list of rhetorical concepts suitable for first year secondary students, including in its final form two major concepts: metonymy and synecdoche, of which $1 \leqslant$ sub-concepts branched

The SRL-based program has proven effective in developing the understudy literary appreciation skills of first year secondary students. This was evident by means of calculating differences between mean scores of students in the pre-post administrations of literary appreciation skills test as a whole and each component skill separately, where the difference was statistically significant at $\because \cdot 1$ level in favor of the post-administration in the literary appreciation test. Effect size of the program was also great 
يسهم تعليم اللغة العربية في صقل شخصية المتعلم، ويساعده على التواصل

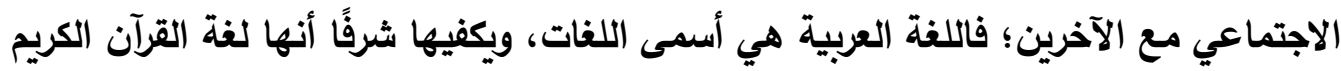

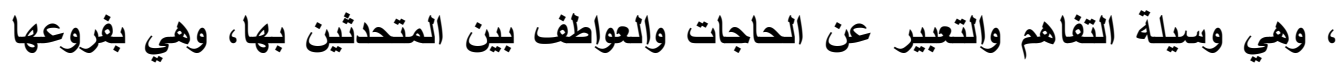
المختلفة - وخاصة النصوص الأدبية- ترقى بمشاعر القارئ أو السامع, وتنظلق بخياله, وتكسبه المعاني السامية والقيم الرفيعة.

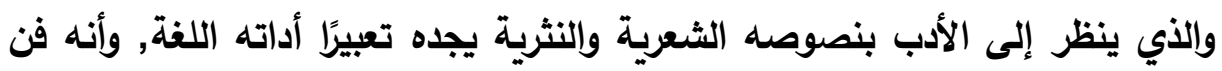

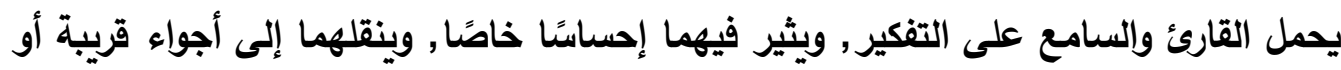
بعيدة من الخيال, فالتخيل حاجة إنسانية؛ إذ إن كل إنسان يتخيل, وخيرهم من نمّى خياله

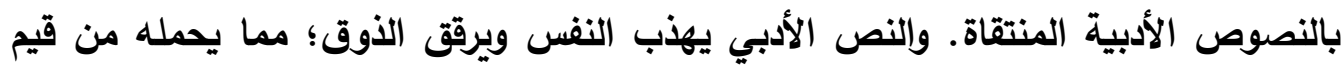

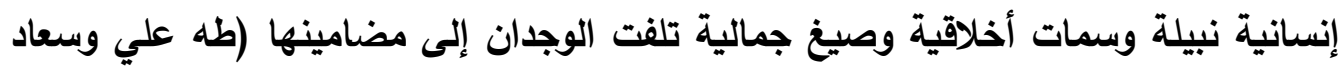

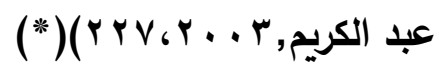
والتذوق الأدبي هو الكيفية التي تهاي صاحبها إلى نقد الأبب، فالتذوق فطرة فُطر

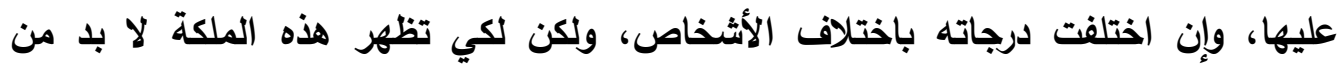

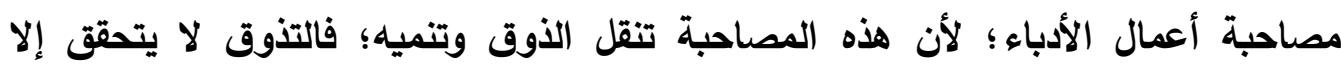

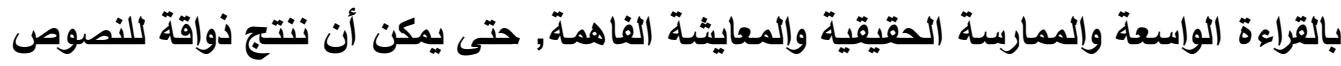

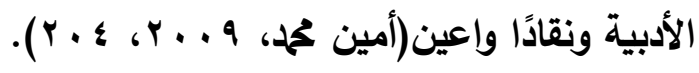

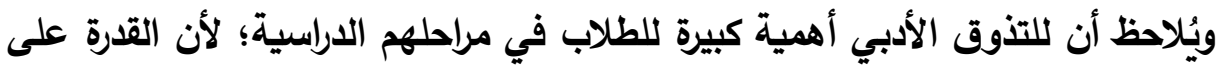

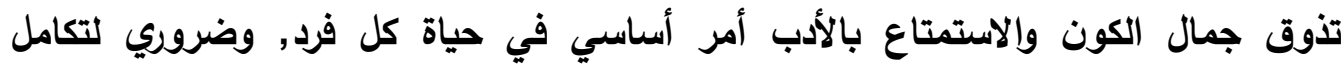

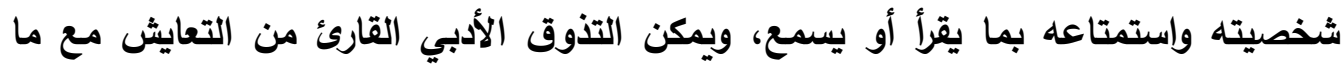
يقرؤه, والتوصل إلى مقصود الأديب منها، والتمييز بين الهادف وغير الهيكن الهادف منها.

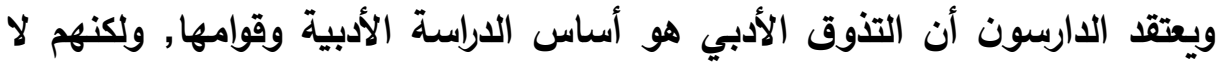

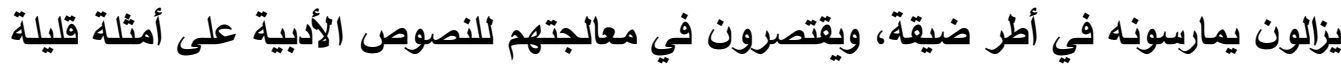

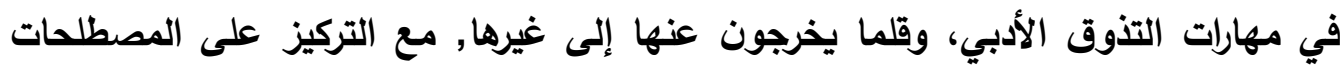

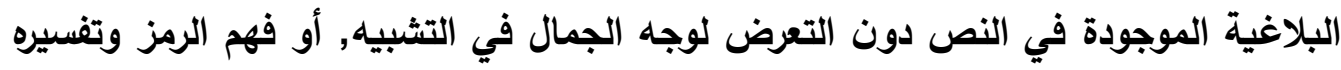

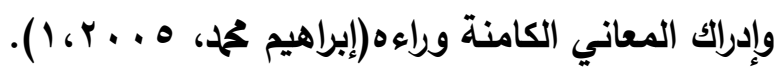




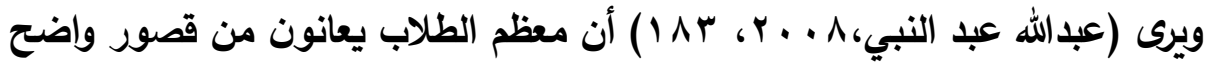
في إتقان مهارات التذوق الأدبي و ضعف في تطبيقها, وتؤكد نتائج دراسات كل من:(أماني

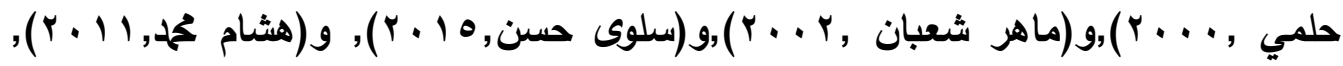

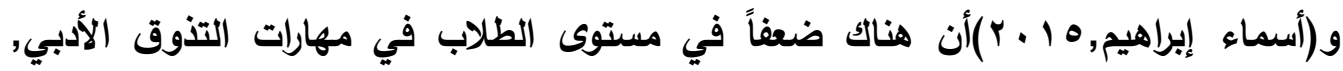

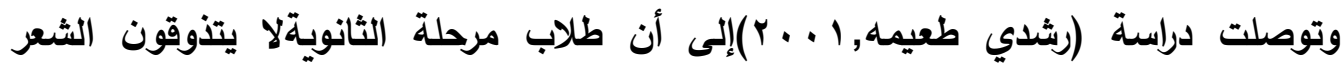
بمفهومه الحقيقي للتذوق.

ويرى (حبيب مونسي, ب . . r, ؛ ) أن من وسائل تنمية التذوق الأدبي إتاحة الفرص المناسبة للطلاب للتعبير عن أحاسيسهم ومشاعرهم في أثناء دراسة النص الأدبي, وخلق الظروف المتاحة لتقييم النص ونقد أجزائه وتقديره, ومساعدتهم على عقد الموازنة بين النصوص، فالمعلم الكفء يستطيع أن يأخذ طلابه نحو التذوق والإحساس بمواطن الجمال.

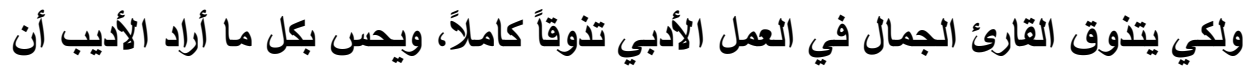
ينقله إليه من عواطف وأفكار ودلالات يجب عليه أن يعرف الوسائل التي هيأت للأديب ذلك. والبلاغة هي العلم الذي يزود القارئ بمعرفة الوسائل التي يستعين بها الأديب في تعبيره،

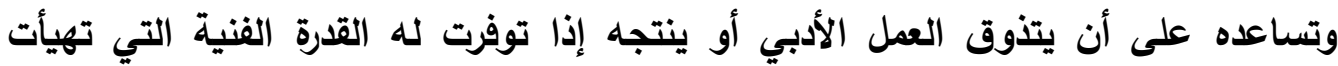

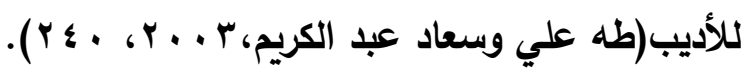
بالتأمل فيما سبق يُلاحظ أن القصور في مهارات التذوق الأدبي يعود إلى إهمال دور

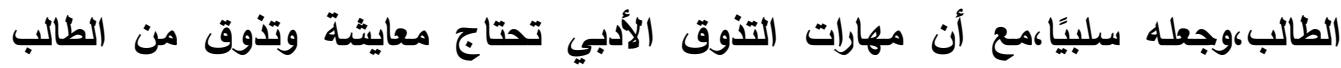
نفسه,وهذا يتطلب طريقة تهتم بالطالب وتساعده على تنمية مهارات التذوق لديه،ويرى الباحث أن الذي قد يساعد الطالب على تنمية مهارات التذوق الادبي لايه هو التعلم المنظم ذاتيًا.

فالتعلم المنظم ذاتيًا يجعل الطالب محور عملية التعلم؛ يخطط أهدافه وينظم تعلمه ويسترجع خبراته السابقة ويربطها بالحالية، ويتوصل بنفسه إلى نواتج التعلم؛ لذلك قد يكون

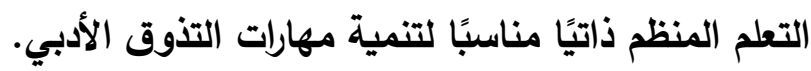

(") يتم التوثيق في هذه الدراسة بذكر (الاسم الأول والثاني للمؤلف، سنة النشر، رقم الصفحة) وتفاصيل كل مرجع مثبتة في قائمة المراجع. 
ومما يؤكد أهمية التعلم المنظم ذاتيًا في علاج القصور في مهارات التذوق الأدبي ما

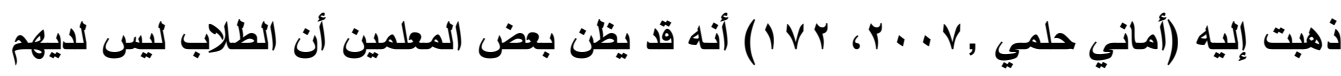

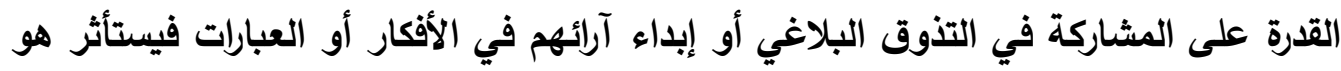

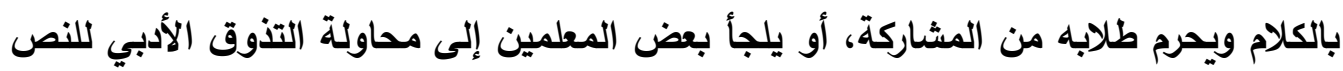

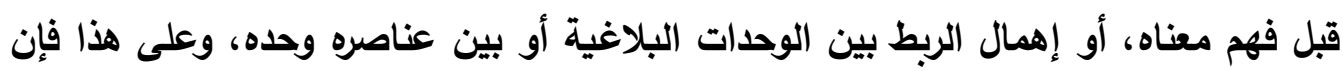

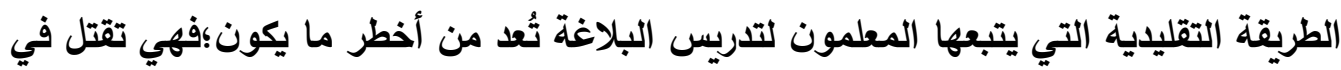

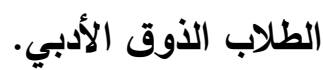
والتعلم المنظم ذاتيًا بأساليبه المختلفة مفيد في كل المراحل الدراسية، إلا أن الحاجة إليه تزداد مع نهاية المرحلة الإعدادية والتحاق الطلاب بالمرحلة الثانوية؛ لأنه يكون مناسبًا أكثر للمراحل العليا من التعليم. ويساعد التعلم المنظم ذاتياً أيضاً في تحقيق مستويات مرتفعة من التحصيل الأكاديمي

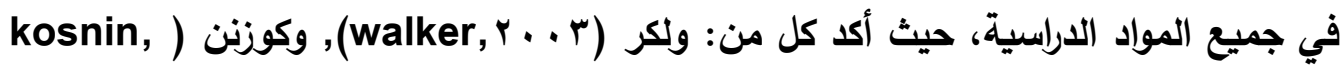

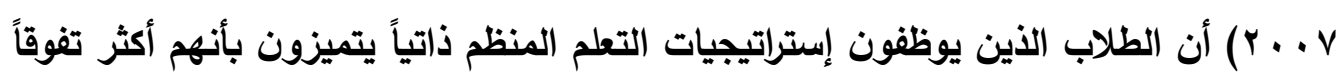
في التحصيل الدراسي في المواد المختلفة عن غيرهم. كما قد أثبتت نتائج بعض الدراسات فاعلية إستراتيجيات التعلم المنظم ذاتياً في إثارة

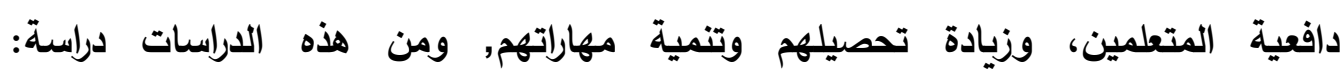

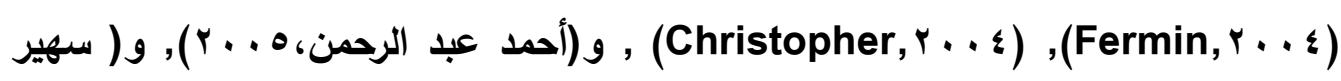

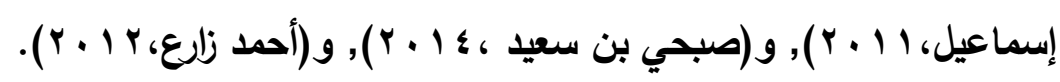

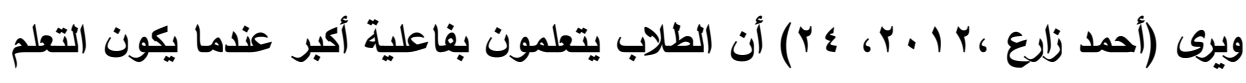

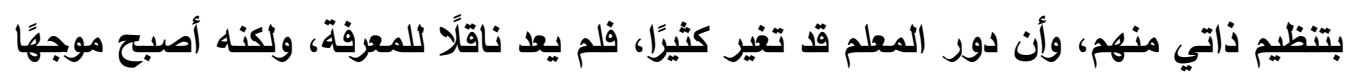
للطلاب؛ لهذا يُلاحظ أن إستراتيجيات التعلم المنظم ذاتيًا تساعد المعلم على تنويع أساليب التدربس. ويستفاد من الدراسات السابقة أن التعلم المنظم ذاتياً يساعد في زيادة التحصيل

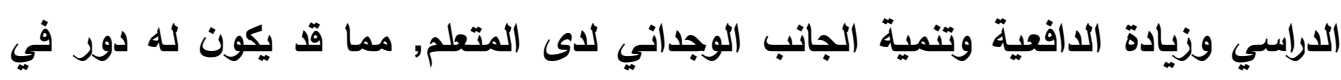
مساعدة المتعلم في تنمية مهارات التذوق الأدبي لايه. 
مشكلة الدر اسة: يمكن تحديد مشكلة الدراسة من خلال:

1- نتائج الدراسات السابقة: فقد قام الباحث بمراجعة بعض الأبحاث والدراسات السابقة التي تناولت مهارات التذوق الأدبي , ومن هذه الدراسات دراسة: (أماني حلمي، .... ...),

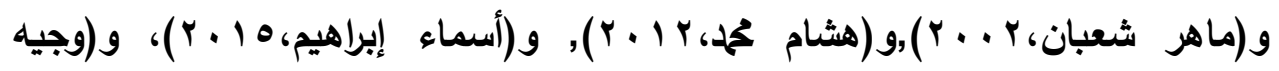

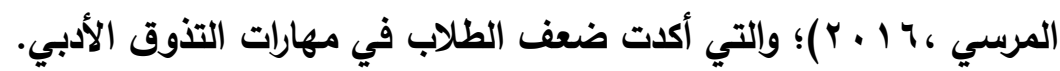

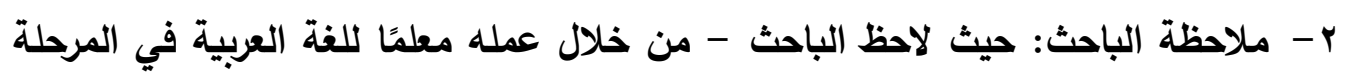

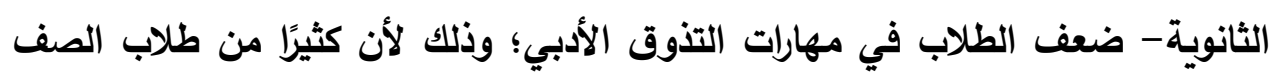

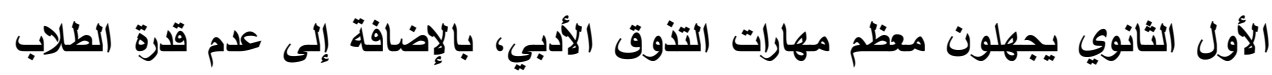
على تذوق ما في النصوص الأدبية من قيم جمالية.

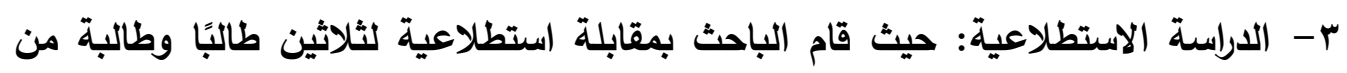

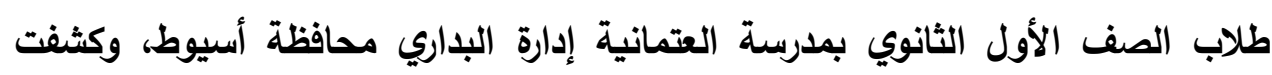
المقابلة عن ضعف اكتساب الطالب لمهارات التذوق الأدبي. وفي ضوء ما سبق تحددت مشكلة الدراسة في ضعف مهارات التذوق الأدبي لاى طلاب

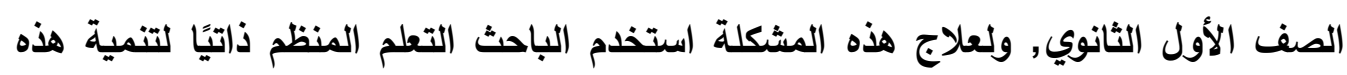
المهارات لايهم. أسئلة الدر استة: سعت الاراسة الحالية إلى الإجابة عن الأسئلة التالية:

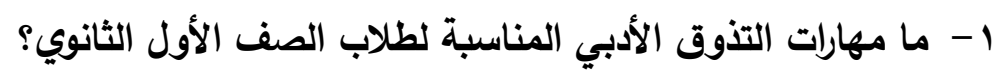
ץ- ما البرنامج القائم على التعلم المنظم ذاتيًا لتنمية مهارات التذوق الأدبي لادى طلاب الابل

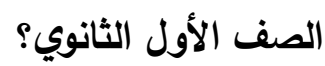
ب- ما فاعلية برنامج قائم على التعلم المنظم ذاتيًا في تنمية مهارات التذوق الأدبي لاى

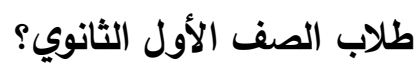
مصطلحات الدر اسة:

ا-التعلم المنظم ذاتياً: يُعرف التعلم المنظم ذاتياً إجرائياً بأنه:عملية يقوم بها طالب الصف

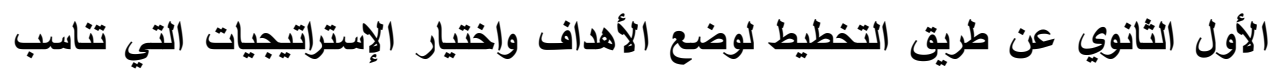

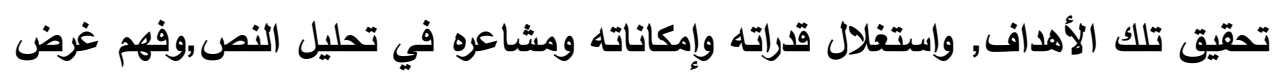
النص, والاستعانة بعاطفة الأديب؛ لاستخلاص مهارات التذوق الأدبي المطلوبة. 
r - مهارات التذوق الأدبي:

تُعرف مهارات التذوق الأدبي إجرائياً بأنها: مجموعة من الأداءات التي تجعل طالب الصف

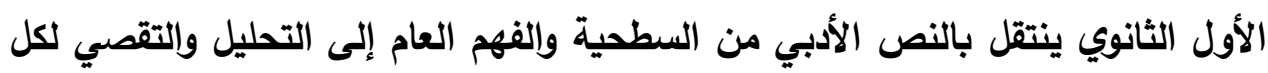
جزء من النص, من خلال معرفة مواطن القوة والضعف, واستخراج الصور الجمالية وفهم التراكيب المكون منها النص بناء على مقومات وأسس البلاغة, وتقاس بالدرجة التي يحصل عليها الطالب في اختبار التذوق الأدبي المعد لذلك.

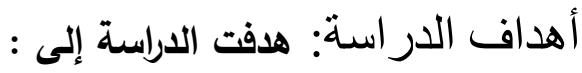
- - تنمية مهارات التذوق الأدبي لاى طلاب الصف الأول الثانوي. ب- تعرف فاعلية البرنامج القائم على التعلم المنظم ذاتيًا في تنمية مهارات التذوق الأدبي

لاى طلاب الصف الأول الثانوي؟

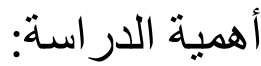

تفيد الاراسة الحالية في تقديم خلفية نظرية عن دور التعلم المنظم ذاتيًا في

تنميةمهارات التذوق الأدبي، كما تفيد كلًا من: الطلاب: من خلال تنمية مهارات التذوق الأدبي لايهم. لالدئ. المعلمين:من حيث تزويدهم ببرنامج قائم على التعلم المنظم ذاتيًا يمكن استخدامه في تنمية مهارات التذوق الأدبي لاى طلابهم. الموجهين: من حيث تطوير أداء موجهي اللغة العربية وإفادة المعلمين بخبراتهم.

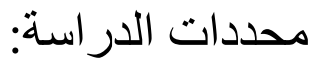
• مجموعة من طلاب الصف الأول الثانوي بمدرسة العتمانية الثانوية المشتركة بمركز

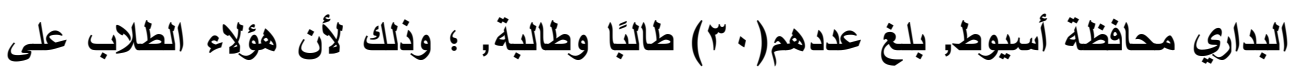
درجة من النمو اللغوي والعقلي تمكن من تنمية مهارات التذوق الأدبي لايهم,وتساعدهم على استخدام التعلم المنظم ذاتيًا.

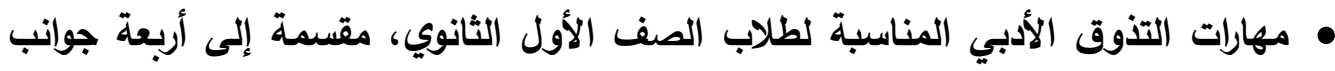
رئيسة, هي: (الجانب الفكري, والجانب البياني, والجانب الوجداني, والجانب الاجتماعي) وبلغ عددها ( • مائيس، مهارة أدائية. 


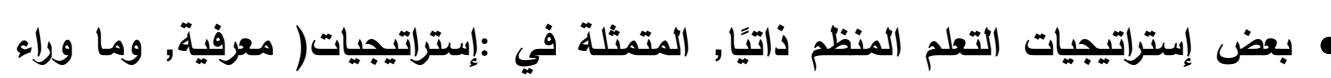

$$
\text { معرفية, مصادر التعلم). }
$$

منهج الدراسة: تم استخدام المنهج التجريبي في اختيار مجموعة الدراسة وتطبيق

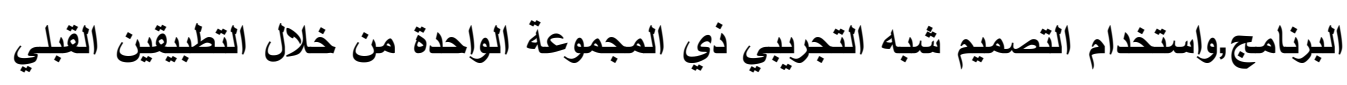
والبعدي لأدوات الدراسة:المناسبة هذا التصميم التجريم للمتغيرات.

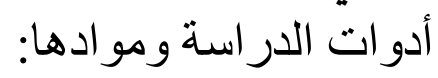

تطلبت الدراسة الحالية إعداد الأدوات والمواد الآتية: (إعداد الباحث)

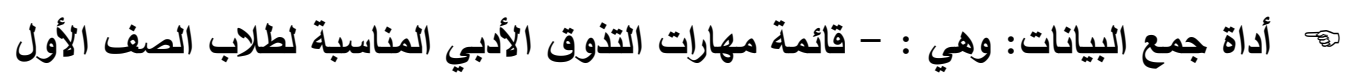

$$
\text { الثانوي. }
$$

$$
\text { هواد الدراسة: }
$$

برنامج قائم على التعلم المنظم ذاتيًا, وتطلب البرنامج إعداد: ( كتاب الطالب - ليل المعلم)

إهـ أداة القياس: وهي : - اختبار التذوق الأدبي لطلاب الصف الأول الثانوي.

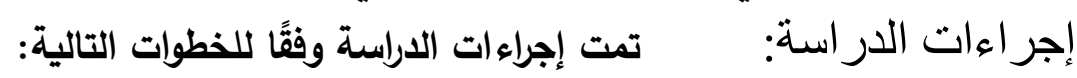
أولا: للإجابة عن السؤال الأول للاراسة, ونصه: "ما مهارات التنوق الأببي المناسبة لطلاب الصف الأولة الأول

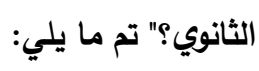
- الاطلاع على الأدبيات التربوية والدراسات السابقة التي تناولت مهارات التذوق الأدبي.

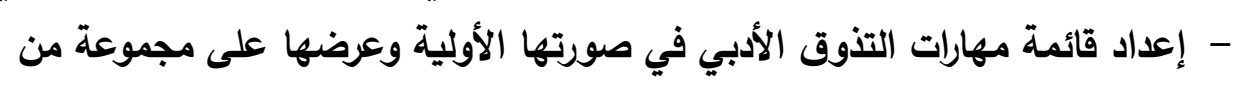

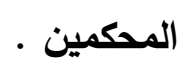
- الوصول إلى القائمة النهائية لمهارات التذوق الأدبي المناسبة لطلاب الصف الأول

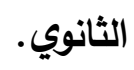

ثانيًا: للإجابة عن السؤال الثاني من أسئلة الدراسة, ونصه "ما البرنامج القائم على التئ

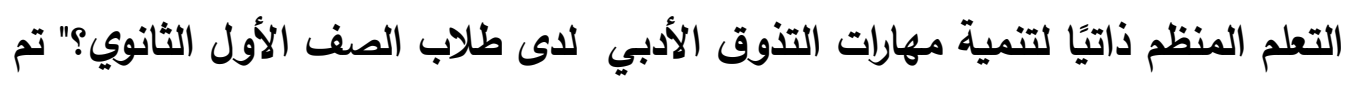
اتباع الإجراءات التالية: 


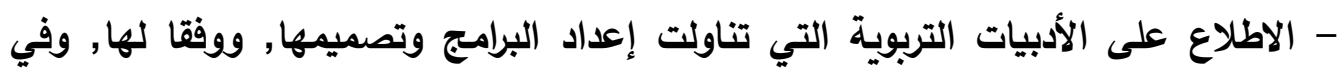

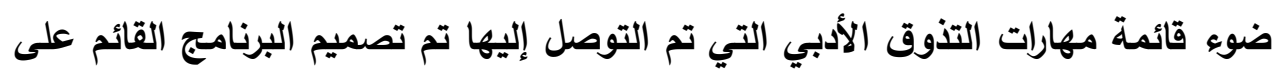
التعلم المنظم ذاتيًا, بحيث اشتمل على:

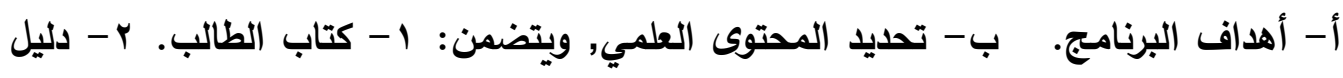
المعلم. - المان

ج- تحديد أساليب التعلم. دـ - الأنثطة التعليمية التعلمية المتطلبة. و - أساليب التقويم.

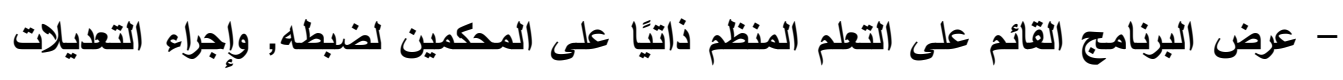
اللازمة في ضوء آرائهم ومقترحاتهم. - التوصل للصورة النهائية للبرنامج القائم على التعلم المنظم ذاتيًا لتنمية مهارات التذوق الأدبي لاى طلاب الصف الأول الثانوي.

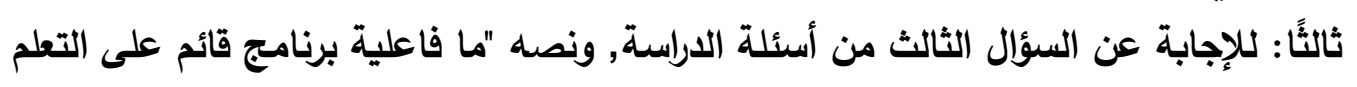

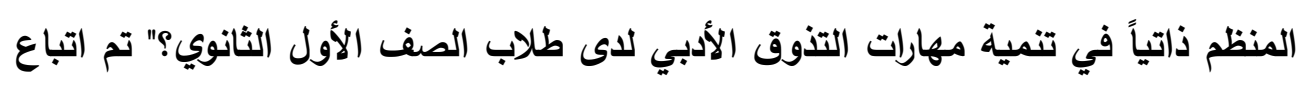

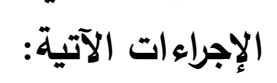

- تحديد مجموعة الدراسة من طلاب الصف الأول الثانوي بمدرسة العتمانية الثانوية

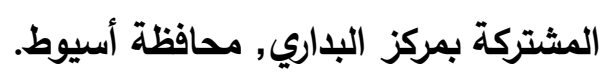

- إعداد أدوات القياس (اختبار مهارات التذوق الأدبي لطلاب الصف الأول الثانوي) في صورتها الأولية.

- عرض أدوات القياس على المحكمين لضبطها, وإجراء التعديلات في ضوء آرائهم

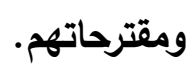

- تطبيق أدوات القياس على مجموعة استطلاعية؛ للتأكد من صدقها وثباتها وحساب زمنها.

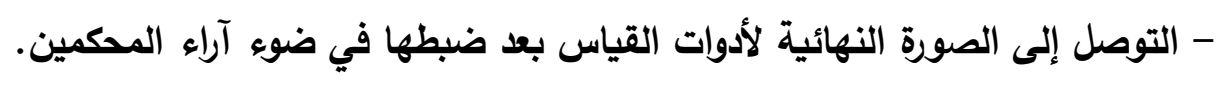
- تطبيق أدوات القياس على مجموعة الداسة تطبيقًا قبليًا.

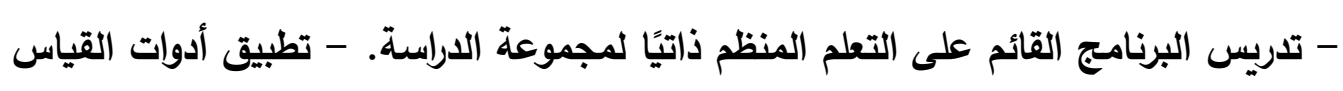
على مجموعة الدارسة بعديًا. - رصد النتائج ومعالجتها إحصائيًا. تحليل البيانات وتفسيرها. تقديم التوصيات في ضوء نتائج الاراسة. 


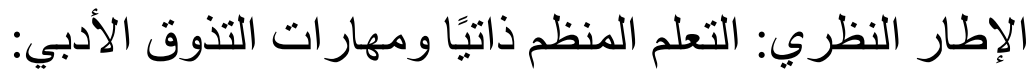

استمرت طرائق التدريس التقليدية لسنوات طويلة, ولكنها لم تحقق الأهداف المرجوة؛

لأن هذه الطرائق تجعل الدور الأساسي للمعلم وتجعل دور الطالب سلبياً، ومثل هذا الزمن الذي كان فيه التعليم عملية روتينية تهدف إلى حصول المتعلم على شهادة فقط - قدئ ولّئ، وأصبح يُنظر إلى المتعلمين على أنهم نشيطون في إعادة تنظيم المادة التعليمية وإعادة بناء المعرفة الموجودة؛ لذلك كان من الضروري تطوير أساليب التدريس؛ حتى تلائم احتياجات المتعلمين، وتراعي الفروق الفردية فيما بينهم، ولكي يتحقق ذلك لا بـ أن يكون الدور الأساسي للطالب الذي يمكنه - بتوجيه من المعلم - أن يتعلم تعلمًا ذاتيًا. مفهوم التعلم المنظم ذاتيًا:

ويرى الباحث أن التعلم المنظم ذاتيًا إجرائيًا هو: عملية يقوم بها طالب الصف الأول الثانوي عن طريق التخطيط لوضع الأهداف المناسبة واختيار الإستراتيجيات التي تناسب تحقيق تلك الأهداف, واستغلال قدراته وإمكاناته ودوافعه ومشاعره في تحليل النص الأدبي, وفهم مقصود الأديب والعاطفة المسيطرة عليه من وراء هذا النص الأدبي؛ بهذف استخلاص مهارات التذوق الأدبي المطلوبـة. مبرر ات استخدام التعلم المنظم ذاتيًا:

ازدادت الحاجة في هذه السنوات الأخيرة على ضرورة تطوير أساليب التدريس ، والتخلي عن طرائق التدريس التقليدية التي تجعل المتعلم سلبيًا وتقتل فيه روح الإبداع والابتكار، والاتجاه إلى طرائق حديثة تركز على المتعلم وأن يُعلم نفسه

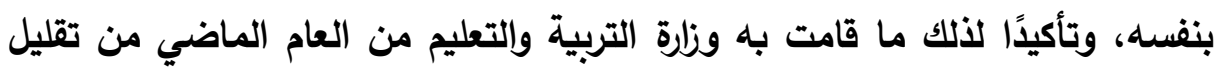
دور المعلم ، وربط الطالب بالوسائل التكنولوجية الحديثة ، وإعداد شباب مفكر يواكب

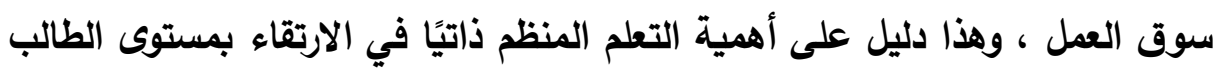

ولا شك في أن الاتجاهات التربوية المعاصرة تنظر إلى الطالب باعتباره محورًا لعملية

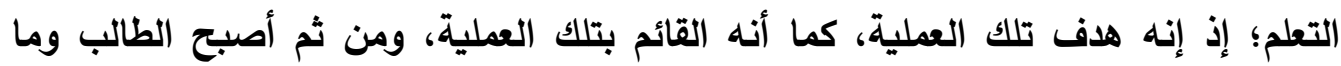
يمتلكه من قدرات ومهارات عاملًا مهمًا يتوقف عليه نجاح العملية التعليمية بأكملها، وبالتالي من الضرورة تنمية ذلك الطالب والعمل على رفع كفاءته، وتعليمه إستراتيجيات تساعده على 
تنمية قدراته وتنظيمها وإحداث تكامل بينها؛ وذلك بهدف تحقيق أقصى استفادة ممكنة منها

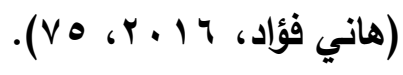

وقد ظهر مصطلح التعلم المنظم ذاتيًا حديثًا في مجال التربية، وأصبح من المصطلحات التي صارت متوائمة مع طبيعة هذا العصر- عصر العولمة والانفجار المعرفي والعلمي - هذا العصر الذي يتطلب إعداد متعلمين قادرين على الإسهام في صياغة أهداف تعلمهم وفي

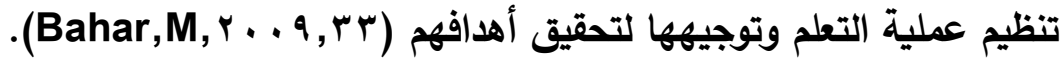

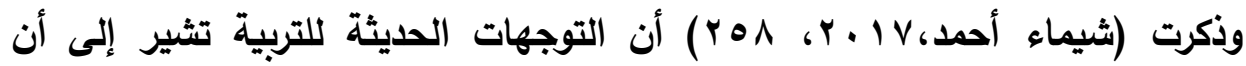
الغايات التربوية للتدريس لا تتحقق إلا بمشاركة المتعلمين أنفسهم ومعرفة كيف يُخططون ويُفكرون، وهذه الغايات تتحقق من خلال التعلم المنظم ذاتيًا. إضافة إلى ما سبق يرى الباحث أن هناك مبررات أخرى لاستخدام التعلم المنظم ذاتيًا, منها: ا-الحد من استخدام الطريقة التقليدية التي تقضي على روح الابتكار والإبداع عند المتعلمين. r - التعلم المنظم ذاتيًا يعود المتعلم الاعتماد على نفسه في عملية التعلم وإبداء رأيه فيها ويراعي الفروق الفردية بين المتعلمين r- شعور المتعلم بالرضا عن تعلمه في ظل التعلم المنظم ذاتيًا وازدياد حبه للعملية التعليمية. ؟ - توصية العديد من الدراسات السابقة بضرورة استخدام إستراتيجيات حديثة من شأنها التركيز على دور المتعلم، وإيجابيته في عملية التعلم. ه- سوق العمل في العصر الحالي يتطلب جيلًا مبدعًا يعتمد على نفسه قاديلها على على حل المشكلات، له شخصية وفكر. مراحل التعلم المنظم ذاتيًا

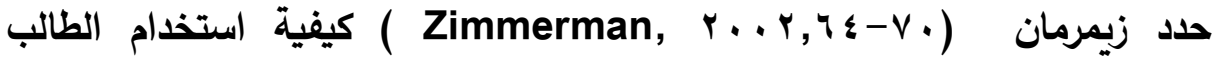
عملياته الخاصة في التعلم، وتوظيف معتقداته الا|فعية ليكون متعلمًا منظمًا ذاتيًا، حيث يتم ذلك وفق المراحل التالية: 
1 - مرحلة التفكير والتخطيط (التجهيز): و يطلق على هذه المرحلة مرحلة التخطيط ووضع

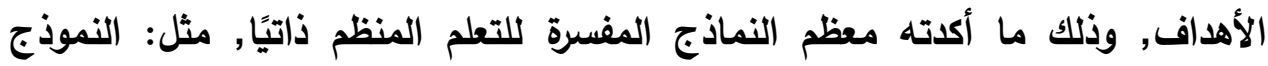
الثلاثي للتعلم المنظم ذاتيًا، ونظرية المعرفة الاجتماعية؛ حيث يتم في هذه المرحلة وضع الأهداف المراد تحقيقها من عملية التعلم، والتخطيط الجيد للوقت والجهد المطلوب

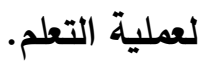
r - مرحلة الأداء: وفيها يتم الضبط الذاتي والملاحظة السلوكية كعناصر أساسية في مراحل الأداء، ثم يقوم المتعلم بتنفيذ الإستراتيجيات التي تم اختيارها في مرحلة التفكير. r- مرحلة الضبط وإلتظيم: وتشير هذه المرحلة إلى محاولة تنظيم المتعلم للجوانب المعرفية والدافعية والسلوك والبيئة؛ من أجل تحقيق الأهداف التي تم تحديدها في مرحلة التفكير والتخطيط, وتتضمن هذه المرحلة الآتي: - الضبط المعرفي: ويتضمن إعادة ترتيب المعلومات بما يجعل عملية التعلم أيسر، واختيار إستراتيجيات معرفية مناسبة. - ضبط الدافعية: ويتضمن تنشيط الدافعية, ودفع مشاعر الملل, والتعامل مع العقبات التي يمكن أن تواجه عملية التعلم, ومن الآليات التي يستخدمها المتعلم حوار الذات أو إقناع الأات بالقدرة علي الفعل. - ضبط السلوك: ويتمثل في محاولة المتعلم لتنظيم سلوكه وملاحظته لله. - الضبط البيئي: ويُشير إلى ضبط المتعلم للبيئة المادية والاجتماعية والنفسية التي فيها التعلم, والتي تساعد على تركيز الانتباه, وهي من الإستراتيجيات المهمة في التعلم المنظم ذاتيًا. ع -مرحلة التقويم الذاتي:وتستخدم في هذه المرحلة التغذية المرتدة,وهي تتضمن التقييمات الأتية وإصدار أحكام على ما تم تعلمه،بمقارنة أداء المهمة ببعض الأهداف التي تم وضعها لعملية التعلم،وفيها يبحث المتعلم عن أسباب الأخطاء التي وقع فيها. خطو ات و إجر اءات التعلم المنظم ذاتيًا وفيما يلي تصور مفصل لمراحل وخطوات استخدام التعلم المنظم ذاتيًا - في الدراسة الحالية- لتنمية مهارات التذوق الأدبي لدى طلاب الصف لألئ لأول الثانوي: المرحلة الأولى: مرحلة الإعداد والتخطيط ووضع الأهداف: وفيها يتم اتباع الآتي: 
1 - تنشيط المعرفة السابقة للطالب؛ حيث يقوم الطلاب بإجابة بعض الأسئلة عن الدرس السابق وربط ذلك بالدرس الجديد.

r - يحدد الطالب الأهداف المراد تحقيقها من الدرس وصياغتها صياغة سلوكية وتكون قابلة •لتحقيق

r- يذكر الطالب قيمة ما سيتعلمه ويذكر توقعاته من وراء ما سيتعلمه. ع - تعريف الطالب بمهارات التذوق الأدبي المراد تحقيقها من خلال تحليل النصوص الأدبية. ه- يتم تعديد زمن التعلم، والأدوات والوسائل المعينة للتعلم. צ- تعريف الطالب بإستراتيجيات التعلم المنظم ذاتيًا, ويختار منها ما يناسب الأهداف التي تم تحديدها. - الارتقاء بهمم الطالب وتثجيعه على تحقيق أهداف الدرس، ويقترح كل منهم مكافأة لنفسه عند تحقيق أهداف الارس. 1 - إدراك الطالب للمهام التي سيتم تعليمها ومدى صعوبتها. المرحلة الثانية: التحليل و التنفيذ: التئي

وتتم هذه المرحلة وفق الخطوات والإجراءات الآتية:

1-يكتب المعلم مهارات التذوق الأدبي المراد تنميتها في هذا الدرس على السبورة . r - يكتب المعلم لطلابه بعض الأبيات الشعرية (ليست من مقرر النصوص) على السبورة. r- يقوم كل طالب بكتابة الأبيات الشعرية في سجل خاص به به. ع - يبدأ كل طالب بقراءة الأبيات أكثر من مرة حتى يصل كل طالب إلى الفكرة العامة للأبيات. ه- قد تختلف الفكرة العامة للأبيات في ظاهرها، لكن المعنى واحد، فمثل هذا لا ينكره المعلم عليهم צ- يقوم الطالب بوضع أسئلة حول هذه الأبيات, بحيث لا تخرج هذه الأسئلة عن مهارات التذوق الأدبي التي تم تحديدها في المرحلة السابقة، وتخص اللون البياني الذي حدده المعلم. V- يأخذ المعلم هذه الأسئلة من الطلاب ويستبعد منها ما لا يتلاءم مع متطلبات الدرس. ^- يتم تحديد كم محدد من الأسئلة, ويطلب من الجميع الإجابة عن هذه الأسئلة. 
9 - يسجل كل طالب إجاباته في كراسته.

ـ 1 - يطلب الطالب من المعلم أو الزملاء المساعدة في قراءة كلمة صعبة صلة في البيت. المرحلة الثالثة: المر اقبة الذاتية:

في هذه المرحلة يتابع الطالب مدى تقدمه في تحقيق الأهداف وملاحظة سلوكه في

أثناء التعلم، ويمكنه التوصل إلى بعض المعوقات ومحاولة التغلب عليها، ويمكن للمعلم تحفيز

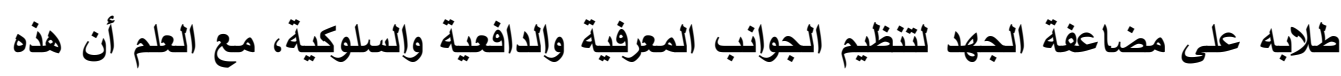

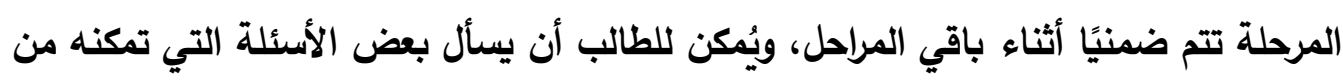

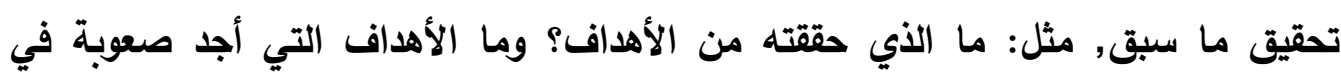

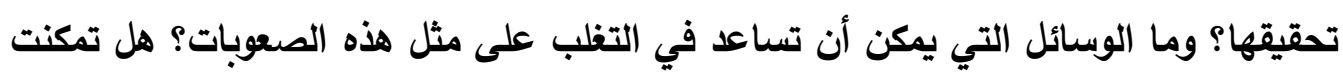

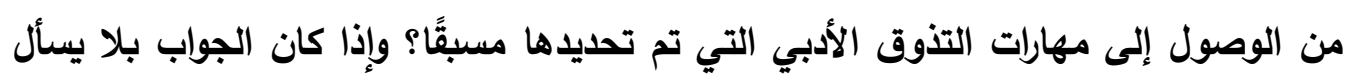

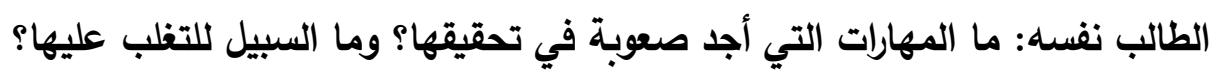

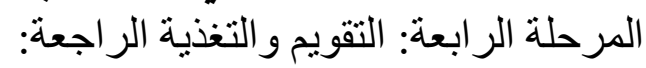
1 - يقوم الطالب بتقييم ذاته، وذلك من خلال مطابقة ما توصل إليه بالأهداف التي حددها مسبقًا.

ץ- يمكن للطالب أن تكون معه قائمة بالإجابات الصحيحة ويطابقها بالإجابات التي يحتوي عليها سجله.

r- يمكن للمعلم في هذه المرحلة أن يُقدم تغذية راجعة لطلابه؛ لتصحيح ما أخفقوا فيه. 


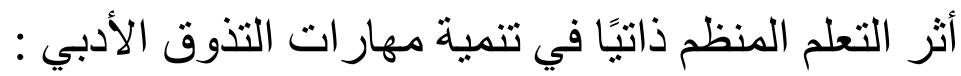

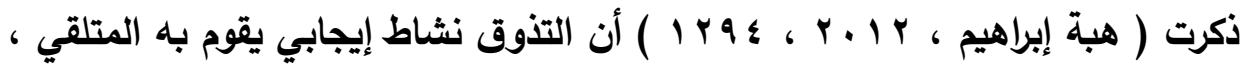
يتطلب توافر مقومات عقلية ووجدانية وجمالية واجتماعية لاى المتلقي ، ومن ثم فإننا في

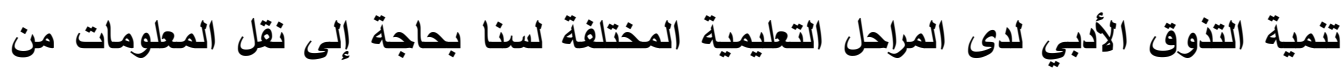
المعلم إلى التلميذ ، بل المهم توفير مواقف التعليم التي تمكن المتعلم من القيام بالنشاط

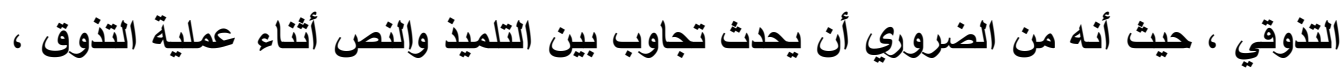
وبالتالي فإن عملية التلقين لا تصلح على الإطلاق في هذه الحالة ، وإنما نحتاج إلى تفعيل

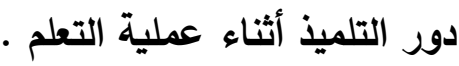

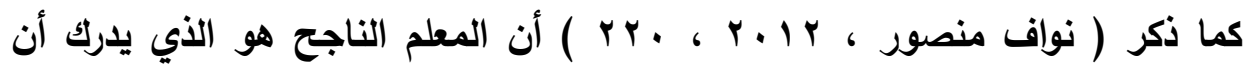
تنمية مهارات التذوق الأدبي لا يمكن أن تتأتي إلا بدراسة الأدب ، وقراءة النماذج الراقية

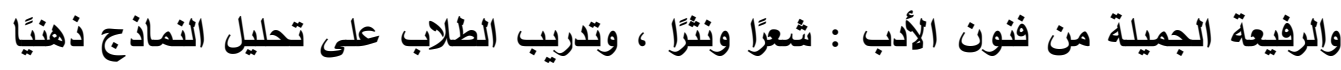
وإبداء آرائهم ليتسنى لهم التعرف على مهاراتهم ومحاولة تحسينها.

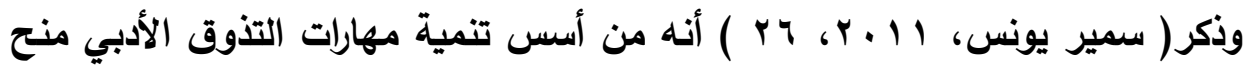
الطلاب حرية في النقاش والحوار، وكذلك إدراك العلل والأسباب التي تجعهه يميلون للعمل الأدبي وقراءة النص غير مرة وتفحصه بتأني ورويّة؛ الإدراك العلاقات بين مكونات العمل الأدبي ، وتدريب الطلاب على فصص العمل ومعايثة الطلاب للأعمال الأدبية الإبداعية.

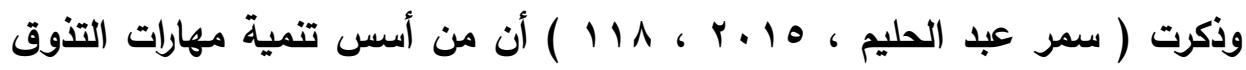

الأببي : 1-مناقثة التلاميذ في مضامين النص الأدبي من حيث الأفكار العامة، والجزئية، ومعاني المفردات اللغوية، وإبراز نواحي الجمال في التعبير وأثره، وهذا يعني أنه لا تذوق دون

$$
\text { فهم المقروء. }
$$

r -تشجيع التلاميذ على المشاركة وحرية الرأي وعدم استئثار المعلم بالعمل منفردًا. r- تدريب التلاميذ على قراءة النص أكثر من مرة واستعراضه بثمولية ،وعناية وتركيز وتأثير

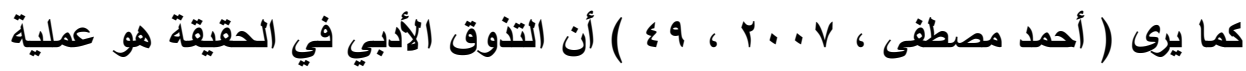
عمدية يقوم بها المتلقي في مواجهة أي عمل أدبي بعد أن يحتثد لها من استعدادات مناسبة 
لنوع العمل، وتهيؤ مناسب للغة العمل وإيقاعه بقصد اكتشاف بنية العمل : الإنشائية ، الخطية ، والدلالية للوصول إلى حكم ذاتي على العمل بالقبول أو الرفض.

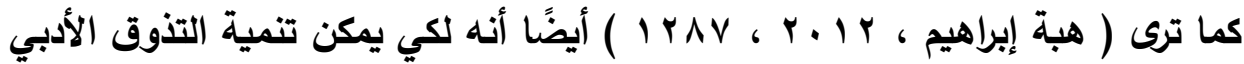
لاى تلاميذ المراحل التعليمية المختلفة ؛ فإنه ينبغي التخلى عن الأسلوب التقليدي في التدريس الذي يعتمد على نقل المعلومات والمعارف وتلقينها للتلاميذ، والعمل على البحث عن النظريات والمداخل الحديثة وأفضل الطرق والأساليب التي تحقق هذه الغاية ، والتي لابد أن تهتم بإيجابية المتعلم ومشاركته الفاعلة في العملية التعليمية ، وتؤكد على أن التعلم لا يمكن أن يكون إلا من خلال المتعلم نفسه، عن طريق تفاعله الدائم أثناء التعلم وتوظيف معارفه القبلية في فهم المعرفة الجديدة .

ومن خلال تحليل ما سبق يتضح أنه يمكن تنمية التذوق الأدبي لاى طلاب المرحلة

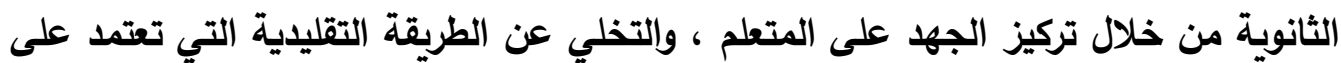
التلقين وتجعل دور الطالب سلبيًا ؛ لأن مثل هذه الطريقة لا يمكن من خلالها أن يكتسب ،لـي الطالب مهارات التذوق الأدبي ؛ وذلك لأن مهارات التذوق الأدبي تحتاج إلى تفاعل الطالب بمشاعره وأحاسيسه مع النص الأدبي ومع عاطفة الثاعر وذلك بتوجيه من المعلم، ومثل هذا هو ما ياعو إليه التعلم المنظم ذاتيًا . أدو ات الدر اسة ومو ادها, و إجر اءات إعنات إعدادها وتطبيقها للإجابة عن أسئلة البحث استخدم الباحث الآتي: أداة جمع البيانات وهي: قائمة مهارات التذوق الأدبي: قام الباحث بإعداد قائمة بمهارات التذوق الأدبي بعد مراجعة الأدبيات والدراسـات السـابقة التي تناولت مهارات التذوق الأدبي، وتم عرضها على مجموعة من الخبراء والمحكمين المختصين

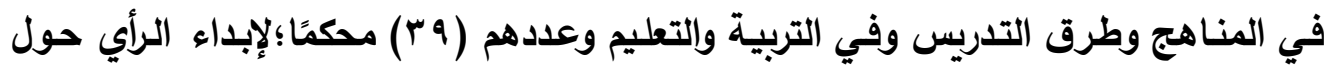
القائمة من حيث مدى مناسبة المهارة لطلاب الصف الأول الثانوي، ومدى السـلامة اللغويـة لهذه المهارات, وقام المحكمون بتعديل وحذف بعض المهارات، ثم قام الباحث بحسـاب الوزن النسبي لقائمة مهارات التذوق الأدبي المراد تنميتها لدى طلاب الصف الأول الثانوي وذلك لاختيار المهارات التي حظيت بنسب اتفاق تصل نسبتها بين المحكمين من( • ـ- . . (\%) ، وحذف المهارات التي هي دون ( •^\%)، وبعد الحذف والتعديل توصل الباحث إلى القائمة في 
صورتها النهائية وهي تضم أربعة جوانب رئيسة ، ومهارات فرعية عددها ( · ب) مهارة. مواد التتريس: أ- إعداد كراسة نثاط الطالب: في ضـوء قائمة مهارات التذوق الأدبي التي تم التوصل إليها، قام الباحث بإعداد

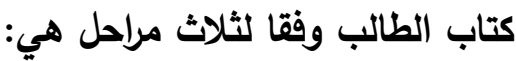

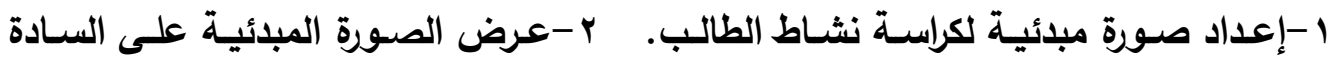

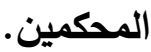

ץ- ب-إجراء التعديلات، وصياغة كراسة نثاط الطالب في صورتها النهائية. أ - إعداد صـورة مبلئية لكراسـة نثـاط الطالب:لقد تم إعداد صورة مبلئيـة لمحتوى هذه فئه

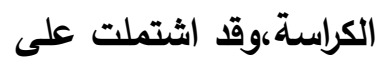
"مقدمة للطالب."محتوى الكراسة. مهارات التذوق الأببي. r-عرض الصورة المبائية على السادة المحكمين :

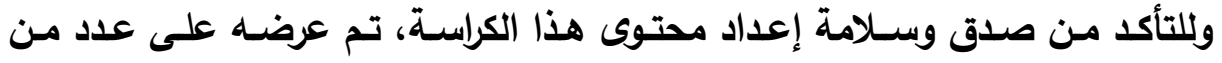

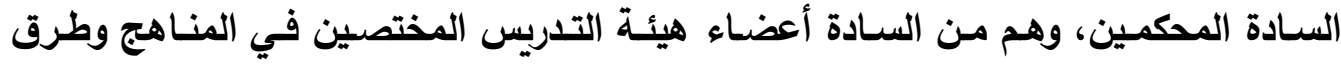
التدريس بصورة عامة، والمناهج وطرق تدريس اللغة العربية بصفة خاصة، وموجهي ومعلمي اللغة العربية، وذلك بهلف إجراء التعليلات المناسبة وفق ما يرونه صوابًًا من حيث:

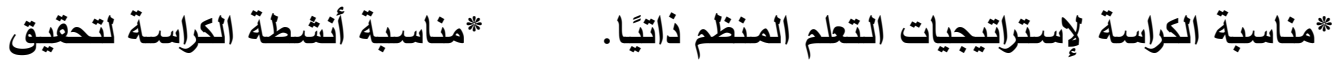

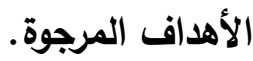
"مناسبة التدريبات والتطبيقات لتحقيق أهداف المحتوى. r- إجراء التعديلات، وصياغة كراسة نثاط الطالب في صورتها النهائية .

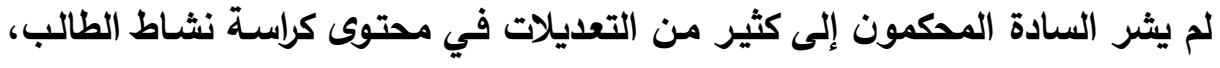
حيث كانت معظم هذه التعديلات شكلية، مثل تعديل صياغة كلمـة،أو استفسار عن كيفية كانية التطبيق، و أشار معظمه إلى جودة الكراسة .

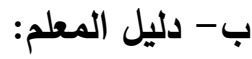
تم عرض دليل المعلم في صورته الأولية على مجموعة من المحكمين المختصين في المناهج وطرق تدريس اللغة العربية, وبعض موجهي ومعلمي اللغة العربية, بلغ عددهم

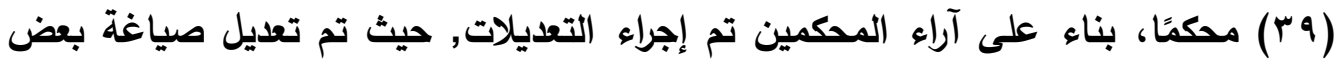


الأهداف التعليمية, وتحديد الزمن المخصص لبعض الأنشطة التعليمية الواردة في الدروس, وبالتالي تم التوصل إلى الصورة النهائية للبرنامج. أداة القياس: إعداد اختبار مهارات التذوق الأدبي لطلاب الصف الأول الثانوي:

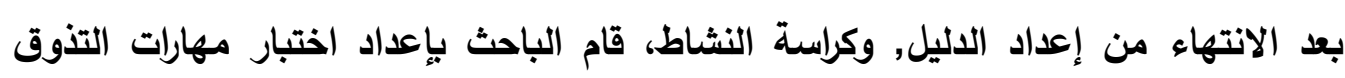

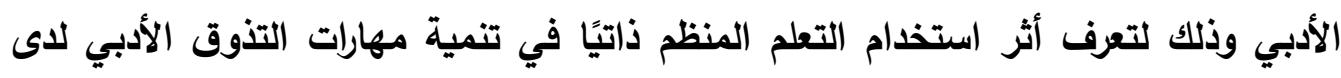
طلاب الصف الأول الثانوي. وقام الباحث بإعداد جلول مواصفات روعي في إعداده الوزن النسبي للموضوعات وكذلك مهارات التذوق الأدبي التي يقيسها، وذلك لتحديد عدد الأسئلة المتضمنة في الاختبار وفقا لتلك المهارات،والجدول التالي يوضح مواصفات الاختبار التحصيلي وعدد الأسئلة لمهارات التذوق. 
أثر استخدام التعلم المنظم ذاتيًا في تنمية مهارات التذوق الأدبي

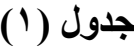

مواصفات اختبار مهارات التذوق الأدبي لطلاب الصف الأول الثانوي

\begin{tabular}{|c|c|c|c|c|c|c|c|}
\hline \multirow{2}{*}{ المئوية } & \multicolumn{5}{|c|}{ 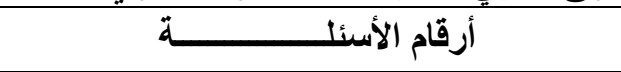 } & \multirow[b]{2}{*}{ المهارات الأدائية } & \multirow{2}{*}{ الجئيسة } \\
\hline & الخزاء & 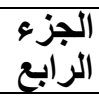 & الثزالث & الثزيء & الألجز & & \\
\hline \multirow{6}{*}{$\%$ r. } & - & - & $1 \leq$ & Ir & - & الأدبد. الفكرة الرئيسة للنص & \multirow{6}{*}{ ال الفكري } \\
\hline & - & ro & - & - & - & الأدبي. ألفكر الفرعية في النص & \\
\hline & YT & - & - & - & $\varepsilon$ & ت باسلوب أدبي. & \\
\hline & - & $r \cdot$ & - & - & r & وانا أخر مناسبًا للنص & \\
\hline & - & - & IV & - & - & الفرضيتفي الترابط بين الألفي. & \\
\hline & - & YI & - & - & - & يُلان الأبيات. & \\
\hline \multirow{5}{*}{$\%$ \%r.r } & - & - & - & - & 1 & الأديبد العاطفة المسيطرة على & \multirow{5}{*}{ الوجدانب } \\
\hline & rर & - & 11 & - & - & ويتر اكيب أثر النصاطفة الأدبي اختيار ألفاظ & \\
\hline & - & - & - & - & 9 & البيلاغية في العاقة بين العاطفة والصبي. & \\
\hline & TV & - & - & - & 7 & ألنصد الأدبِيمة التعبيرية للَكَّمة في & \\
\hline & - & - & - & - & $\Lambda$ & يُّماذا؟ إلى أي التعبيرين اجمل & \\
\hline \multirow{5}{*}{$\%$ \% } & - & - & 10 & - & $\mu$ & أنصد الآدبي. الصورة البيانية في & \multirow{5}{*}{ 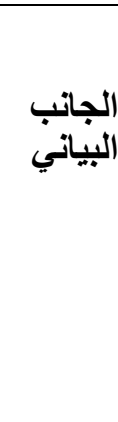 } \\
\hline & rq & - & - & $1 \%$ & - & ألبيانية و الغرض سمال البلاغي منها. & \\
\hline & - & YT & - & $1 \cdot$ & - & في النص ما توحي به الصور البيانية & \\
\hline & $r$. & - & - & - & - & وَفْرق بين الاستُعارة التصريحية & \\
\hline & - & - & - & 11 & - & ورالمشبده بـه. الثشبه بين المشبه & \\
\hline \multirow[t]{4}{*}{$\% r$} & - & YY & 17 & - & - & القصديدة القيم والاتجاهات في & \multirow{4}{*}{ الاجنمان } \\
\hline & - & TE & - & - & 0 & الاحتماعيةمن سنمات الأدلِ النص. & \\
\hline & - & - & - & - & V & 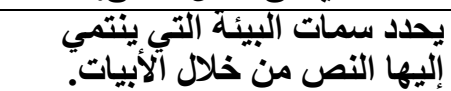 & \\
\hline & - & - & 19 & - & - & تُشكيل التشبيَه والاستعارة. الاجتمي في & \\
\hline
\end{tabular}


رُوعي في صياغة تعليمات الاختبار السهولة والوضوح, ومناسبتها لمستوى الطلاب, وتوضيح الهدف من الاختبار, وتحديد طريقة الإجابة عن أسئلة الاختبار تحديدًا دقيقًا, وتمثلت التعليمات الخاصة بالطلاب الذين يُطبق عليهم الاختبار في توجيههم إلى الأداءات

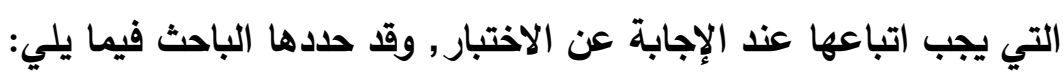
*قراءة كل سؤال جيدًا لتعرف المطلوب منهم. *عدم البدء في الإجابة عن أسئلة الاختبار حتى يُؤَنْ لهم. "توعيتهم بأن هذا الاختبار لا يُستخدم إلا لغرض البحث العلمي.

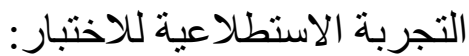

بعد إجراء التعديلات على الاختبار تم تطبيقه على مجموعة استطلاعية- غير

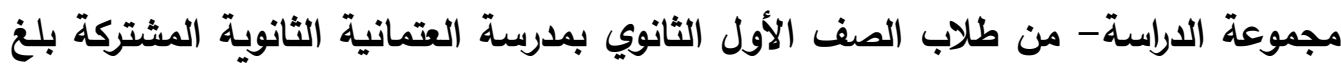
عددها (·r) طالبًا وطالبة؛ حيث تم تطبيق اختبار التذوق الأدبي على المجموعة الاستطلاعية ورصد النتائج, وذلك لحساب صدق الاختبار, وحساب معامل الثبات, وحساب

$$
\text { زمن الاختبار. عدق الاختبار : ( ـالصدق المنطقي (صدق المُحَكمين): }
$$

للتأكد من صدق الاختبار؛ تم عرضه على مجموعة من المُحَكمين المختصين في الاري المناهج وطرق تدريس اللغة العربية وبعض موجهي اللغة العربية ومعلميها بلغ عددهم (ra) محكمًا, وقد تم التأكد من صدقها.

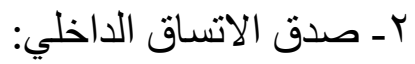

للتأكد من صدق الاتساق الداخلي لاختبار مهارات التذوق الأدبي تم تطبيقه على مجموعة استطلاعية قدرها (· (r) طالبًا وطالبة, وتم حساب معامل ارتباط بيرسون بين كل فقرة من فقرات الاختبار ودرجة كل جانب رئيس للاختبار وكذلك الارجة الكلية للاختبار، كما هو موضح بالجدولين التاليين: 
أثز استخدام التعلم المنظم ذاتيًا في تنمية مهارات التذوق الأدبي ..

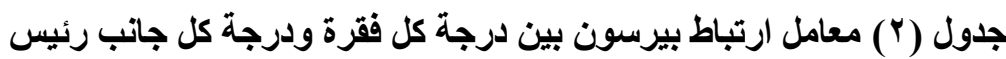

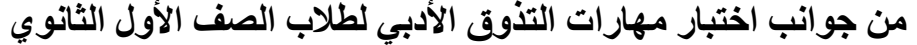

\begin{tabular}{|c|c|c|c|c|c|c|c|}
\hline الاجتماعى & رقأم السؤل & لالبان & رقمث & & السؤال & & رأسؤم \\
\hline$* * . V 94$ & - ج & $* * .790$ & ج-1 & $* * .9 Y \wedge$ & ج & $* *, V \cdot Y$ & r- \\
\hline$* *, . \leq \vee \leq$ & V-I & $* *, . V \vee 1$ & جr-1 & $* * . \wedge \neg 7$ & ج-1 & $* . .777$ & צ- \\
\hline$* *, . \wedge \vee 0$ & ج"r-r & $* *, . \vee \vee \neg$ & r-r & $* * \bullet .0 \wedge 9$ & ^-1 & $* . . \leqslant 7$. & جr-r \\
\hline$* * . \wedge r \Delta$ & جr-ז & $* *, . \vee \vee 7$ & ج-r. & $* *, .9,9$ & 9-1ج & $* *, .7 \leq \leq$ & جr-1 \\
\hline$* *, \wedge \circ 1$ & T-ז & $* *, V \bullet \leq$ & جr-r & $* * .9 Y 7$ & جrי_ט & $* * . .09 r$ & جr-ז \\
\hline \multirow[t]{4}{*}{$* * . \wedge$ Y } & 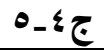 & $* *, . \leqslant \Lambda$. & 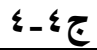 & $* * .010$ & r_ö & $* *, . \vee \wedge$ & ج - \\
\hline & & $* *, .7 \vee r$ & ج_-ם & $* *, V \Psi$ & جם+r & $* *, . \vee \vee q$ & r-\& \\
\hline & & $* *, V \leqslant 0$ & ج_o & & & $* * .791$ & T_\& \\
\hline & & & & & & $* * . .0 Y \wedge$ & جo-1 \\
\hline
\end{tabular}

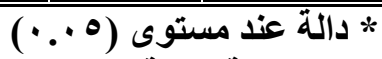

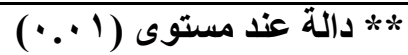

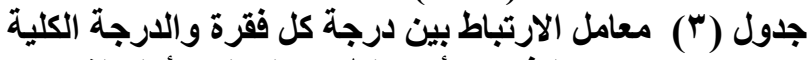

لاختبار مهارات التذوق الأدبي لطلاب الصف دف الأبن الأول الثانوي

\begin{tabular}{|c|c|c|c|c|c|}
\hline معامل الارتباط & رقم السؤال & معامل & رقم السؤال & معامل الارتباط & رقؤم \\
\hline$* *, . \wedge \wedge \wedge$ & ج צ & $* * .017$ & r-r & $* *, . \wedge \wedge r$ & ج1-1 \\
\hline$* * .779$ & T-\& & $* . . \leqslant 9$. & T-r & $* * .07 \varepsilon$ & r-l \\
\hline$* * .011$ & צ- & $* * . . \leqslant 9 V$ & $\varepsilon-Y$ & $* *, . \vee \wedge \wedge$ & جا \\
\hline$* *, . \vee \wedge \wedge$ & ט_\{ & $* * . \Delta \mu r$ & جr-1 & $* * .017$ & ج \\
\hline$* *, . \wedge 1 \mu$ & جـ & $* * . \Delta \mu \mu$ & جr-r & $* *, . \Lambda \cdot \varepsilon$ & ج ج \\
\hline$* *, . \leqslant V V$ & جo-1 & $* *,.\rceil \wedge \mu$ & جr-r & $* *, \Lambda \cdot \varepsilon$ & ج \\
\hline$* . \mu V V$ & ج_oם & $* * .011$ & جr-צ & $* . . \leqslant 7$. & V-I \\
\hline$* * .779$ & جם r. & $* *, . \wedge \wedge \wedge$ & ج_r & $* *$. IV0 & ج- ج \\
\hline$* *, . \wedge \mu r$ & ج_- & $* *, . \vee \wedge \wedge$ & جr-ז & $* *, . \wedge \mu r$ & ج- \\
\hline$* *, . \wedge \wedge \wedge$ & ج_o & $* * . \Delta \mu r$ & 1-צج & $* * \bullet . \diamond Y I$ & جr-1 \\
\hline
\end{tabular}

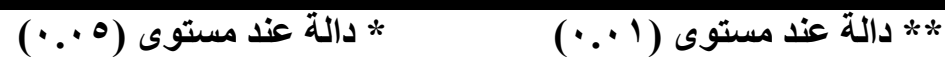

يتضح من الجدولين السابقين أن جميع قيم معاملات الارتباط للاختبار كانت دالة

عند مستويي (1 +..), و(0... )؛ مما يدل على صدق الاتساق الداخلي لاختبار مهارات

التذوق الأدبي لطلاب الصف الأول الثانوي. ثباث الاختبار : ت ت

تم حساب ثبات اختبار مهارات التذوق الأدبي باستخدام معادلة "ألفا كرونباخ", حيث طُبق الاختبار على مجموعة استطلاعية بلغ عددها (.ب) طالبًا وطالبة, وقد بلغ معامل 
الثبات للاختبار (1^. .) وهي نسبة دالة عند مستوى (1 ...), ويدل ذلك على ارتفاع نسبة

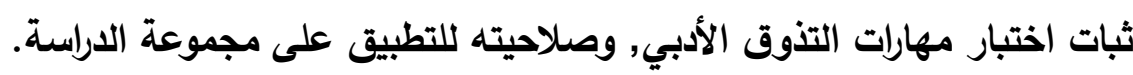

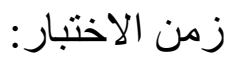

قام الباحث بحساب الزمن المناسب للإجابة عن أسئلة الاختبار, عن طريق تسجيل الإنيل

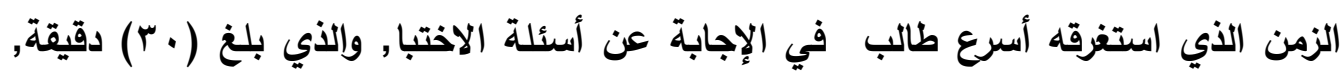

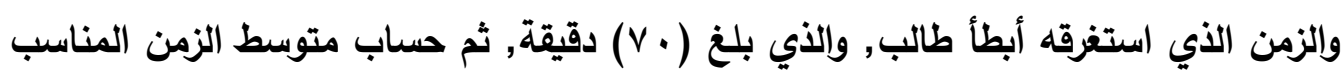

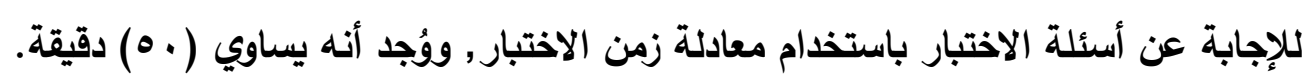

$$
v \cdot+r \text {. }
$$$$
\text { زمن الاختبار }
$$

\section{تصحيح الاختبار:}

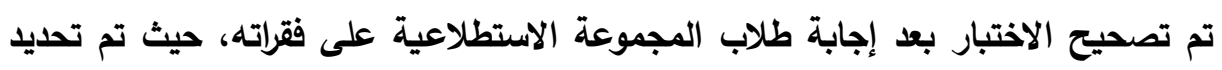
(درجتين) لكل مفردة من مفردات الاختبار، وبذلك تكون الارجة التي حصل علئه الابنها الطالب محصورة

$$
\begin{aligned}
& \text { بين( صفر - مיا) درجة. } \\
& \text { رابعًا: تجربة الدراسة: } \\
& \text { مجتمع الدراسة: }
\end{aligned}
$$

تكون مجتمع الدراسة من طلاب الصف الأول الثانوي بمدرسة العتمانية الثانوية

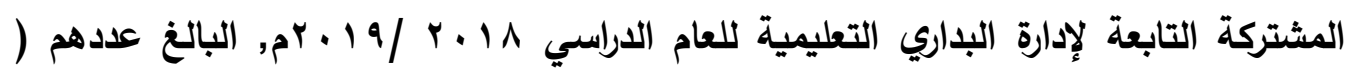

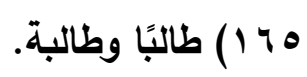

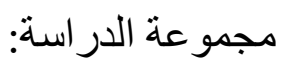

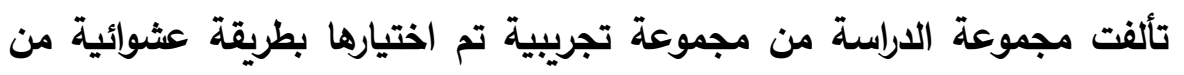

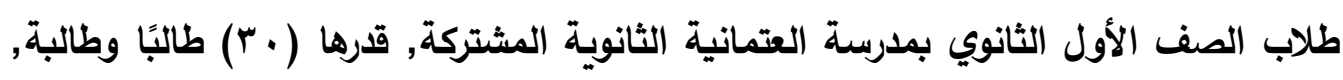
وهم طلاب وطالبات فصل (1/1) (1/). 


$$
\text { زمن تطبيق الدراسة: }
$$

قام الباحث بتطبيق البرنامج القائم على التعلم المنظم ذاتيًا خلال الفصل الدراسي

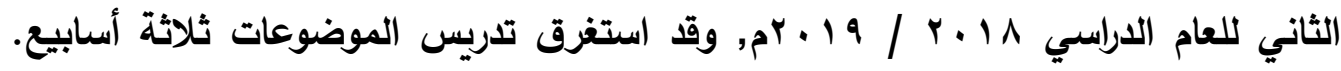
والجدول التالي يوضح الخطة الزمنية لتطبيق الدراسة. جدول (؛ ) الخطة الزمنية لتجربة الدراسة على مجموعة الارية استة من طلاب الصف الأول الثانوي

\begin{tabular}{|c|c|}
\hline الفترة الزمنية & التطبيق \\
\hline 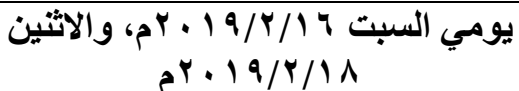 & التجربة الاستطلاعية \\
\hline 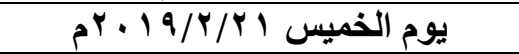 & التطبيق القبلي لاختبار التذوق الأدبي \\
\hline 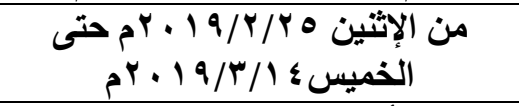 & تطبيق البرنامج على مجموعة الدرسة \\
\hline الأربعاء • • 19/T/Y • & التطبيق البعدي لاختبار التذوق الأدبي \\
\hline
\end{tabular}

وتم إجراء المعالجة الإحصائية عن طريق الإلئ الحاسب الآلي باستخدام البرنامج

Statistical Package for الإحصائي "SPSS" (الحزمة الإحصائية للعلوم الاجتماعية .(Social Sciences

وقد استلزمت الدراسة استخدام المعادلات الإحصائية التالية:

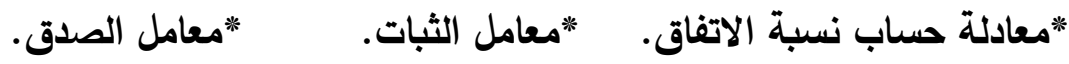
*معادلة حساب زمن تطبيق الاختبار. *المتوسط الحسابي. *الانحراف المعياري. *اختبار "ت" " معادلة حجم الأثر.

$$
\text { نتائج الدر اسة و تفسير ها }
$$

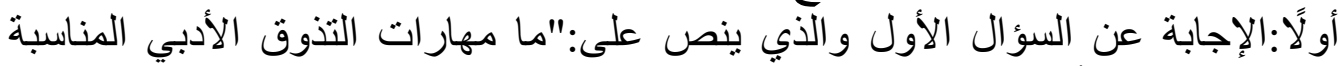

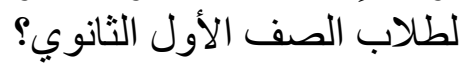
قام الباحث بتحديد قائمة مهارات التذوق الأدبي، بالاعتماد على البحوث والدراسات

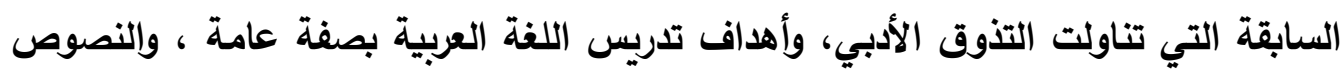
الأدبية بصفة خاصة، والتي تشير إلى بعض هذه المهارات التي تدعو المعلم لأن يعمل على

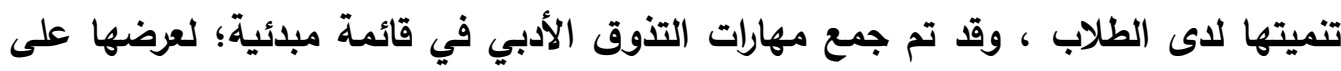
مجموعة من المحكمين المختصين، وبعض موجهي اللغة العربية ومعلميها؛ وذلك بهدف لهي التوصل إلى القائمة في شكلها النهائي، ومن ثم تم التوصل إلى قائمة مهارات التذوق الأدبي المناسبة لطلاب الصف الأول الثانوي وبلغ عددها ( • ب) مهارة أدائية . 


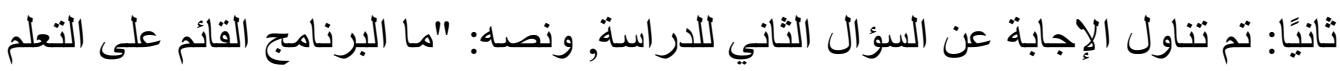

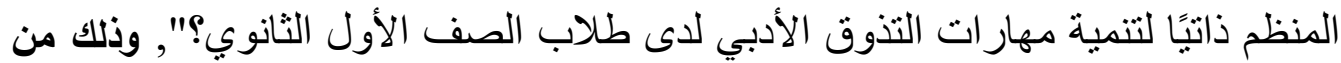
خلال الإجراءات التي جاءت في فصل (أدوات الدراسة وموادها, وإجراءات إعدادها)؛ حيث تم إعداد البرنامج القائم على التعلم المنظم ذاتيًا, وذلك في ضوء الصورة التهرة النهائية لقائمة مهارات التذوق الأدبي, وعدد من المصادر التي تناولت بناء المناهج والبرامج التعليمية وتصميمها, والإطار النظري والمفاهيمي.

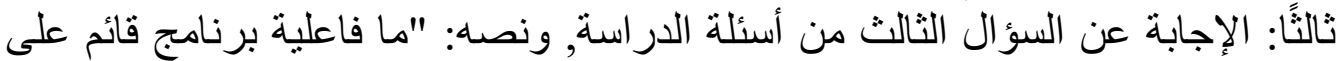

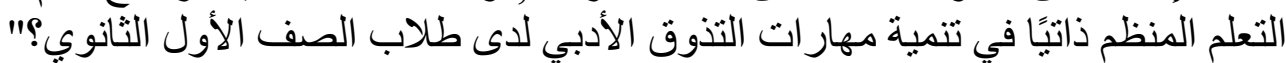

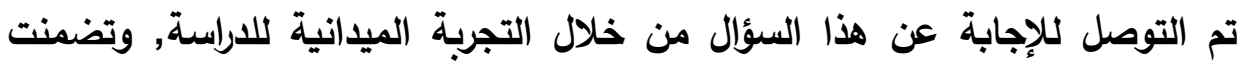
الإجابة عنه الكثف عن فاعلية البرنامج القائم على التعلم المنظم ذاتيًا في تنمية مهارات التذوق الأدبي, حيث تم التوصل إلى الصورة النهائية لاختبار التذوق الأدبي لطلاب الصف الأول الثانوي, ثم تحديد مجموعة الدراسة, وتطبيق أدوات الدراسة قبل تدريس البرنامج وبعده, ومعالجة البيانات الإحصائية للتطبيقين القبلي والبعدي على مجموعة الدراسة من خلال حساب ما يلي: * المتوسط الحسابي والانحراف المعياري لدرجات طلاب مجموعة الدراسة في اختبار مهارات التذوق الأدبي قبل تدربس البرنامج. * المتوسط الحسابي والانحراف المعياري لارجات طلاب مجموعة الدراسة في اختبار مهارات التذوق الأدبي بعد تدريس البرنامهج. * حساب الفرق بين متوسطي درجات الطلاب في كل من التطبيقين القبلي والبعدي لاختبار مهارات التذوق الأدبي من خلال حساب قيمة "ت" ودلالتها الإحصائية. ت تعرف حجم الأثر للبرنامج بعد حساب قيمة "ت" هن الت 
وفيما يلي عرض لتلك الخطوات كالتالي:

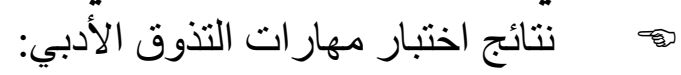

يوضح الجدول التالي المتوسط الحسابي والانحراف المعياري وقيمة "ت" ودلالتها لارجات أفراد مجموعة الدراسة في التطبيقين القبلي والبعدي في اختبار مهارات التذوق الأدبي, حيث (ن = • ب ).

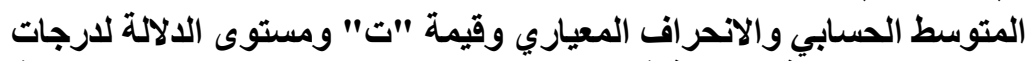

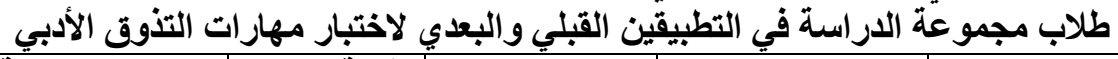

\begin{tabular}{|c|c|c|c|c|c|}
\hline مستوى الدلالة & قيمة "ت" & المجموعة (ن) & 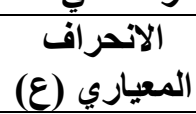 & 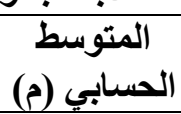 & التطبيق \\
\hline \multirow{2}{*}{ دالة عند مستوى } & \multirow[t]{2}{*}{$£ 1 . \S \vee \wedge$} & \multirow[t]{2}{*}{$r$} & $r .7 \leq 0$ & IY.s. & القبلي \\
\hline & & & r.rqo & OQ.V. & البعدي \\
\hline
\end{tabular}

يتضح من الجدول السابق وجود فرق بين متوسطي مجموع درجات طلاب مجموعة

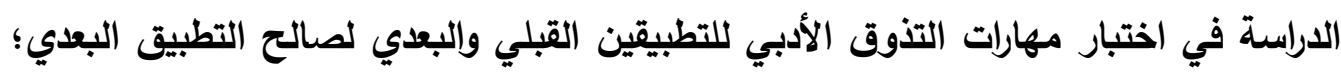
حيث بلغ المتوسط في التطبيق القبلي للاختبار (• ـ. I I), بينما بلغ في التطبيق البعدي

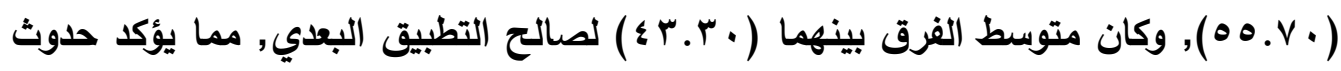
تحسن في الجانب الأدائي لمهارات التذوق الأدبي ككل لدى تلاميذ مجموعة الدراسة بعد تطبيق البرنامج.

كما يتضح وجود فرق دال إحصائيا بين متوسطي درجات الطلاب مجموعة الدراسة في التطبيقين القبلي والبعدي لاختبار مهارات التذوق الأدبي ككل لصالح التطبيق البعدي عند

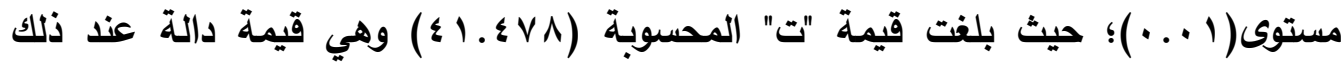
المستوى, وهذا يدل على أن هناك تحسنًا واضحًا في الجانب الأدائي لمهارات التذوق الأدبي ككل.

وبالنسبة للمهارات الفرعية التي تكون منها اختبار مهارات التذوق الأدبي, وبيان الفروق بين متوسطات الارجات, فيمكن بيانها من خلال الجدول التالي الذي يوضح المتوسط الحسابي والانحراف المعياري وقيمة "ت" ودلالتها لدرجات أفراد مجموعة الدراسة في التطبيقين القبلي والبعدي للاختبار في المهارات الفرعية لمهارات التذوق الأدبي مفصلة,حيث 
أثر استخدام التعلم المنظم ذاتيًا في تنمية مهارات التذوق الأدبي

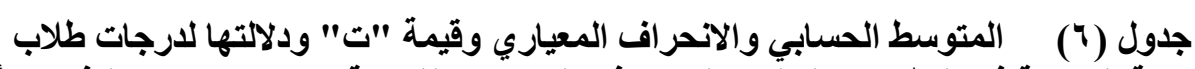

\begin{tabular}{|c|c|c|c|c|c|c|c|c|c|}
\hline \multirow{2}{*}{ الأثرُ } & \multirow{2}{*}{ 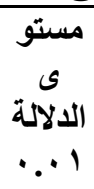 } & \multirow{2}{*}{$\begin{array}{c}\text { المجمو أفراد } \\
\text { (ن) }\end{array}$} & \multirow{2}{*}{ قيمة ت } & \multirow{2}{*}{ المتوق بين } & \multicolumn{2}{|c|}{ التطبيق البعدى } & \multicolumn{2}{|c|}{ التطبيق القبلي } & \multirow{2}{*}{ الرئيس } \\
\hline & & & & & $\varepsilon$ & r & $\varepsilon$ & p & \\
\hline$\ddot{v}^{9}$ & دالة & $r \cdot$ & r9. & $11.9 \mathrm{~V}$ & $1 . r \Delta \wedge$ & $17 . \wedge \mathrm{V}$ & Trug & $\varepsilon .9$. & الفكري \\
\hline$\because 9$ & دالة & $r$. & $r 1 . \leqslant V T$ & $\Lambda . V r$ & $1 . \varepsilon \cdot 1$ & 1r.o. & $1.9 v V$ & $r . v V$ & الوجدانى \\
\hline$\ddot{r}$ & دالة & $r \cdot$ & $1 V . v \cdot q$ & $1 \cdot . r$ & $1 . Y 1 V$ & 10.4 & r.TIY & $\varepsilon . V r$ & البياني \\
\hline$\because 9$ & دالة & $r \cdot$ & $r \leqslant . q \wedge \vee$ & $\Lambda .0 r$ & .910 & $11 . r$. & 1.0 .1 & Y.VV & الاجتماعي \\
\hline$\ddot{i}^{9}$ & دالة & $r$. & $\leqslant 1 . \leqslant \vee \wedge$ & $\varepsilon r . r$ & ס & $00 . V$. & T. & Ir.s. & ككل الاختبار \\
\hline
\end{tabular}

يتضح من الجدول السابق ما يلي:

بالنسبة لمهارات الجانب الفكري: بلغ متوسط درجات الطلاب مجموعة الدراسة في التطبيق القبلي لها (.9. ؛ ), بينما بلغ متوسط درجات المجموعة في التطبيق البعدي

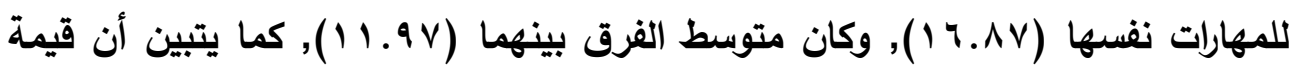

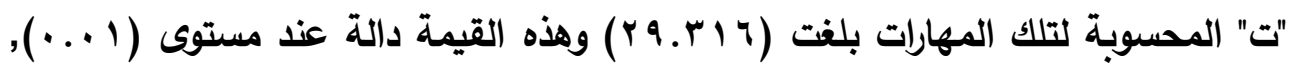
وبحساب قيمة "ت" ودلالتها يتضح وجود فرق دال إحصائيًا بين متوسطي درجات الطلاب(مجموعة الاراسة) في التطبيقين القبلي والبعدي لمهارات الجانب الفكري لصالح التطبيق البعدي, مما يشير إلى أن هناك تحسنًا ملحوظًا في الجانب الأدائي لمهارات الجانب الفكري لاى مجموعة الدراسة من طلاب الصف الأول الثانوي بعد تطبيق البرنامج

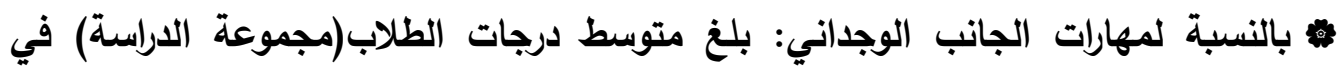
التطبيق القبلي لها (r.VV), بينما بلغ متوسط درجات المجموعة في التطبيق البعدي

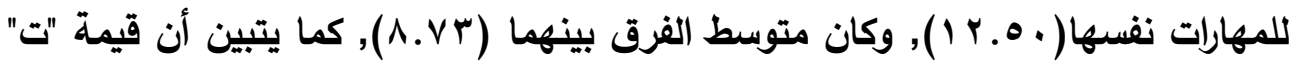

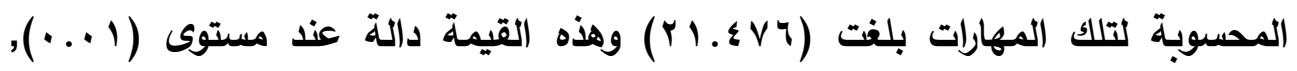
وبحساب قيمة "ت" ودلالتها يتضح وجود فرق دال إحصائيًا بين متوسطي درجات الطلاب(مجموعة الدراسة) في التطبيقين القبلي والبعدي لمهارات الجانب الوجداني لصالح 
التطبيق البعدي, مما يشير إلى وجود تحسن في الجانب الأدائي لمهارات الجانب الوجداني لاى مجموعة الدراسة من طلاب الصف الأول الثانوي بعد تطبيق البرنامج.

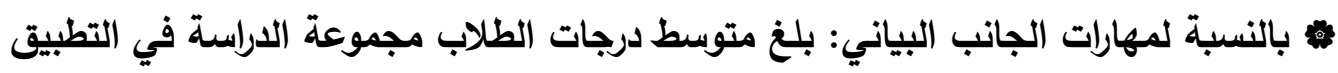
القبلي لها (VY.VY) ), بينما بلغ متوسط درجات المجموعة في التطبيق البعدي للمهارات

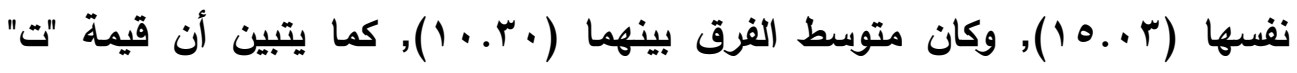

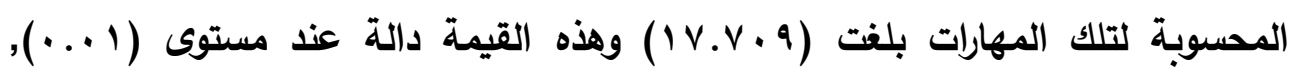
وبحساب قيمة "ت" ودلالتها يتضح وجود فرق دال إحصائيًا بين متوسطي درجات التلاميذ

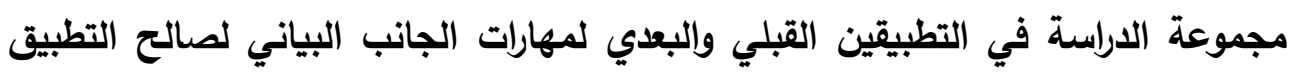
البعدي, مما يثير إلى أن هناك تحسنًا ملحوظًا في الجانب الأدائي لمهارات الجانب البياني لاى مجموعة الدراسة من طلاب الصف الأول الثانوي بعد تطبيق البرنامج.

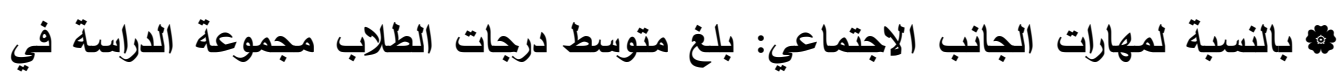

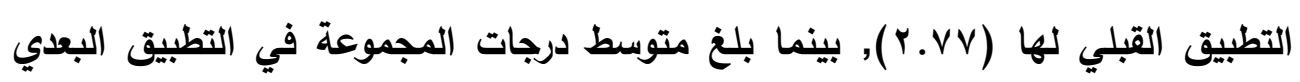

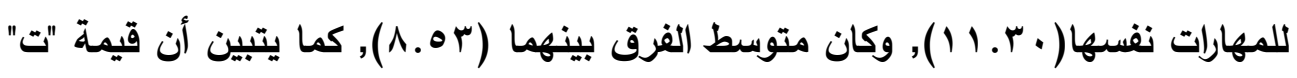

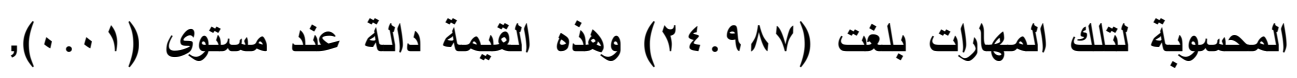
وبحساب قيمة "ت" ودلالتها يتضح وجود فرق دال إحصائيًا بين متوسطي درجات الطلاب(مجموعة الدراسة) في التطبيقين القبلي والبعدي لمهارات الجانب الاجتماعي لصالح التطبيق البعدي, مما يثير إلى أن هنائ تحسنًا واضحا في الجانب الأدائي

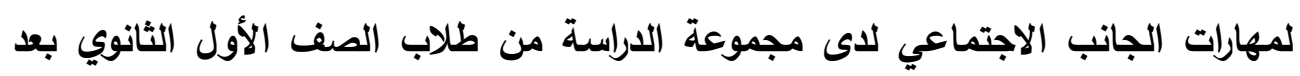
تطبيق البرنامج. مبحساب حجم أثر البرنامج في الجاتب الأدائي لمهارات التذوق الأدبي ككل الذي تم حسابه من خلال الاختبار, وُجد أن قيم حجم الأثر دالة بصور كبيرة,مما يؤكد فاعلية

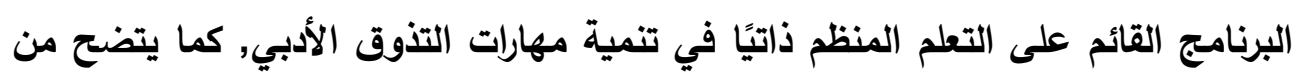

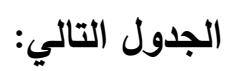


أثر استخدام التعلم المنظم ذاتيًا في تنمية مهارات التذوق الأدبي

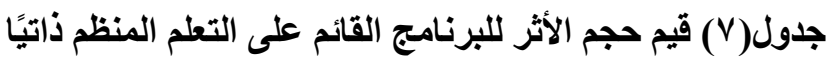
في تنمية مهارات التذوق الأدبي لاى طلاب الصف الصف الأول الثانوي

\begin{tabular}{|c|c|c|}
\hline دلالة حجم الأثر & قيمة حجم الأثر & المهارة \\
\hline دال بصورة كبيرة & $\cdot .9 \mathrm{~V}$ & الجاتب الفكري \\
\hline دال بصورة كبيرة & .97 & الجاتب الاجتماعى \\
\hline دال بصورة كبيزة & $.9 \leq$ & الجانب الوجداني \\
\hline دال بصورة كبيرة & $\because 94$ & الجانب البياني \\
\hline دال بصورة كبيرة &. .91 & مهارات التذوق ككل \\
\hline
\end{tabular}

تتضح من الجدول السابق قيم حجم الأثر للبرنامج ودلالته فيما يتعلق بالجانب الأدائي لمهارات التذوق الأدبي على اختبار مهارات التذوق الأدبي, حيث بلغت قيم حجم الأثر

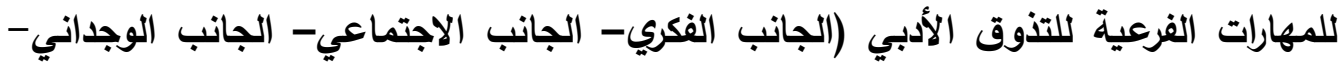

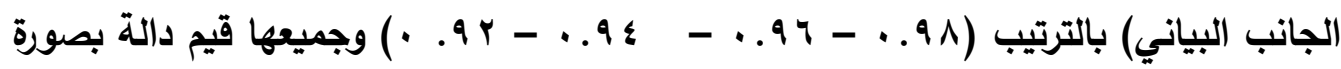

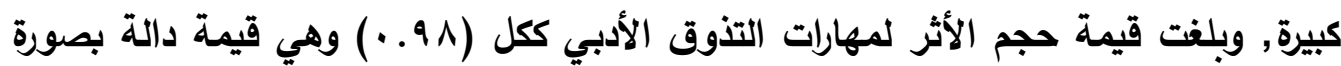
كبيرة؛ مما يدل على أن للبرنامج أثرًا كبيرًا في تنمية مهارات التذوق الأدبي لاى الطلاب مجموعة الدراسة بعد تطبيقه, وهذا الأثر دليل على فاعلية البرنامج القائم على التعلم المنظم ذاتيًا في تنمية مهارات التذوق الأدبي. من خلال ما تم عرضه من نتائج لاختبار مهارات التذوق الأدبي, يتضح وجود فرق دال إحصائيًا بين التطبيقين القبلي والبعدي لاختبار التذوق الأدبي لطلاب الصف الأول الثانوي لصالح التطبيق البعدي, ويتبين ذلك في نتائج اختبار "ت"؛ حيث جاءت الدلائة عند مستوى (1 (.) في النتيجة الإجمالية لاختبار مهارات التذوق الأدبي ككل, وكذلك في المهارات الفرعية للجوانب (الفكري- الاجتماعي- الوجداني- البياني) التي تكون منها الاختبار, مع وجود فرق واضح بين متوسطي مجموع درجات الطلاب مجموعة الاراسة في التطبيقين القبلي والبعدي لصالح التطبيق البعدي. وظهر أن هناك فاعلية للبرنامج في تنمية مهارات التذوق الأدبي, واتضح من خلال حساب حجم الأثر حدوث تحسن ملحوظ في مهارات التذوق الأدبي لاى طلاب الصف الأول الثانوي من خلال تطبيق البرنامج القائم على التعلم المنظم.

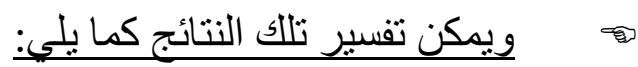
ترجع فاعلية البرنامج القائم على التعلم المنظم ذاتيًا في تنمية مهارات التذوق الأدبي لاى طلاب الصف الأول الثانوي إلى عدة عوامل, منها: 
* الاعتماد عند إعداد البرنامج على أسس إعداد البرامج التعليمية وتصميمها, وكذلك أسس تدريس

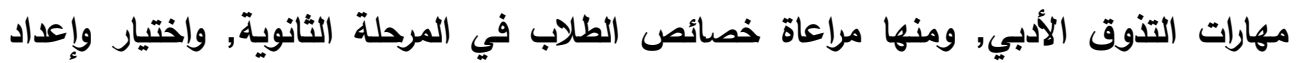

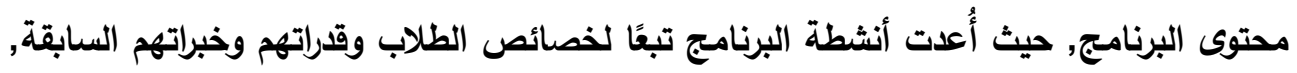

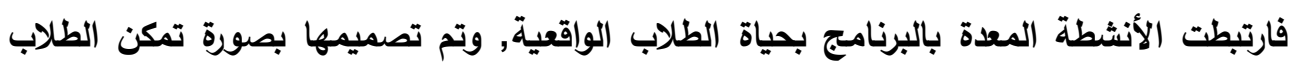

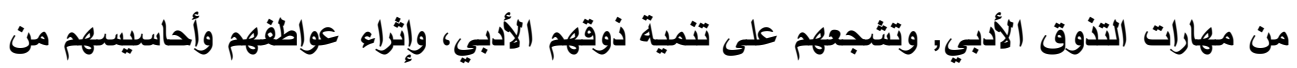

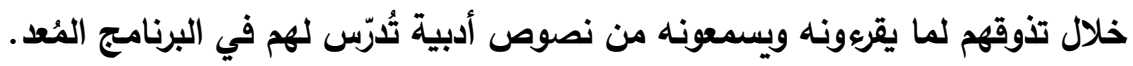

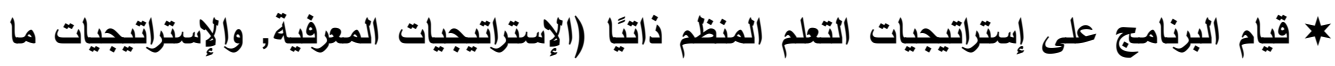
وراء المعرفية, وإستراتيجيات مصادر التعلم)؛ حيث ركزت أنثطة هذه الإستراتيجيات على تنمية داتئي مهارات التذوق الأدبي لاى الطلاب. * التنويع بين الخطوات المتبعة في تدريس موضوعات البرنامج باستخدام إستراتيجيات التعلم المنظم

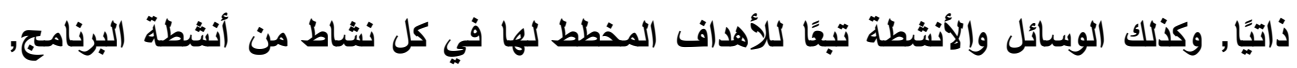

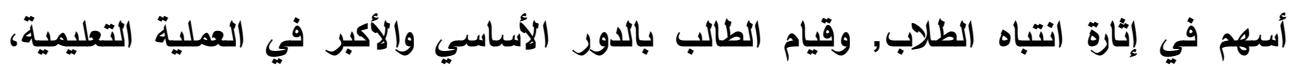

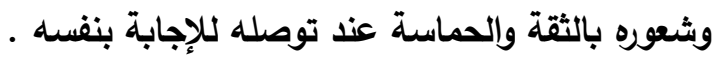

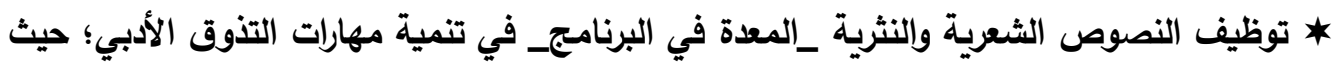

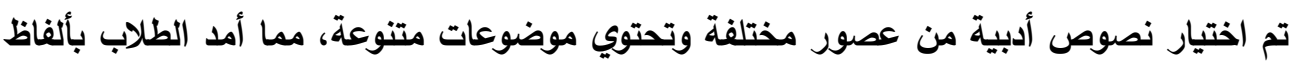

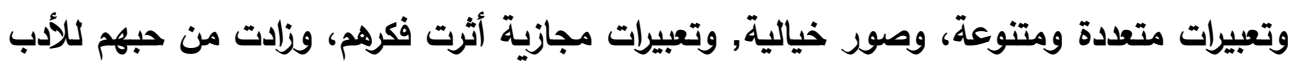
العربي، وأعطتهم فرصة للنقد الأدبي. وتتفق نتائج الدراسة الحالية مع نتائج الدراسات السابقة التي أكدات أنه يمكن تنمية مهارات

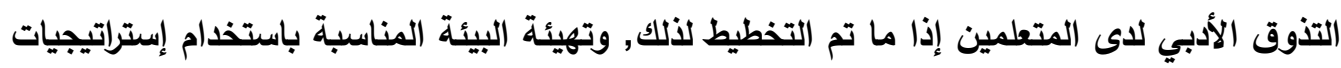

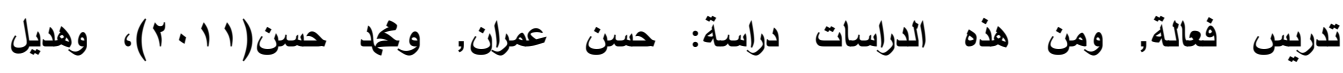

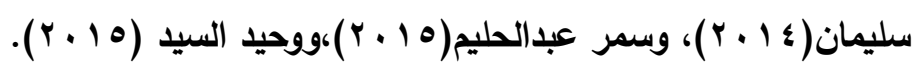

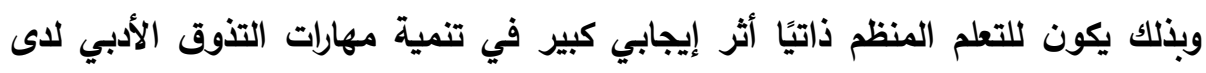

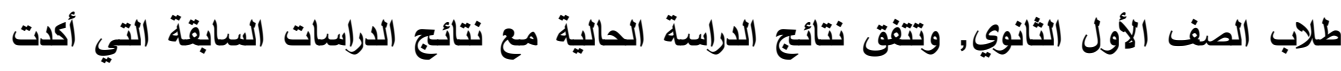

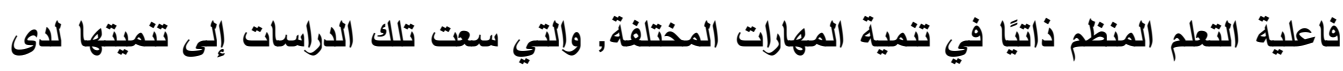

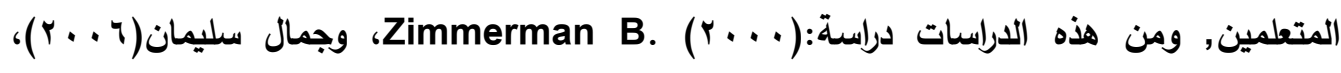

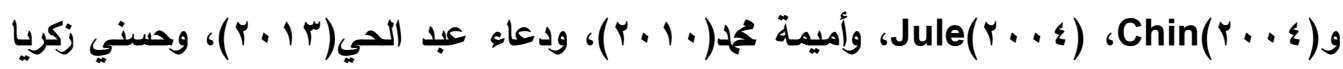

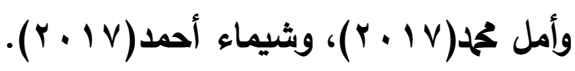




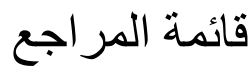

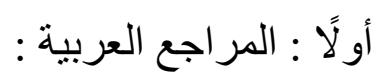

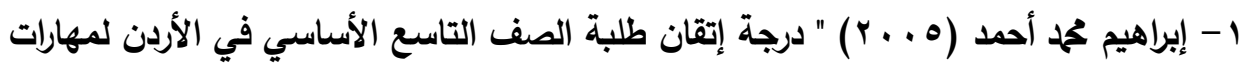

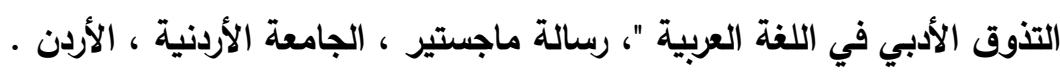

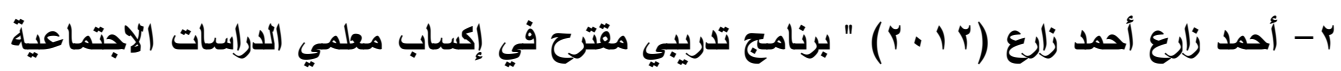

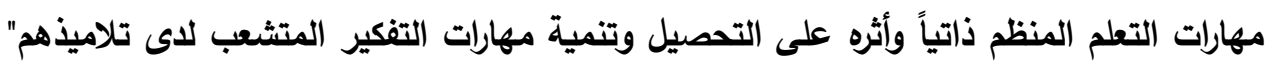

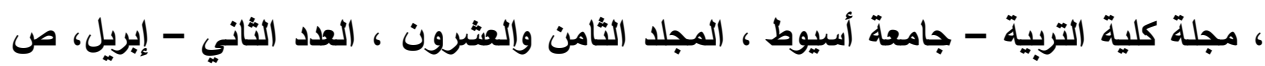

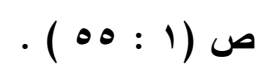

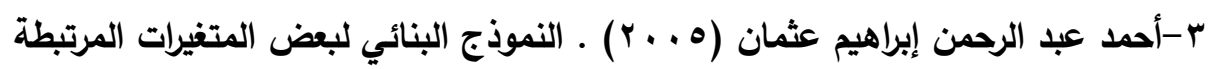
باستراتيجيات التعلم المنظم ذاتياً لاى طلاب المرحلة الثانوية" . مجلة كلية التربية بالزقازيق-

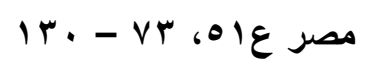

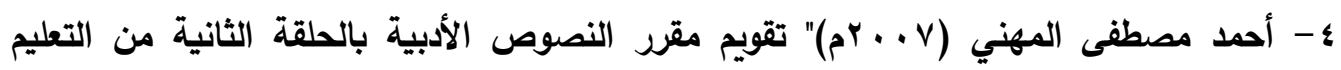

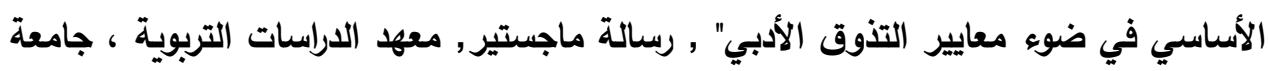

القاهرة.

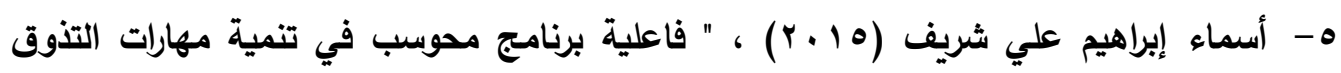

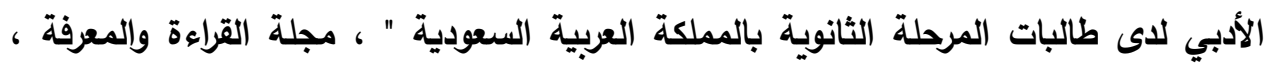

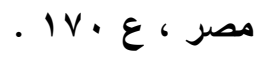

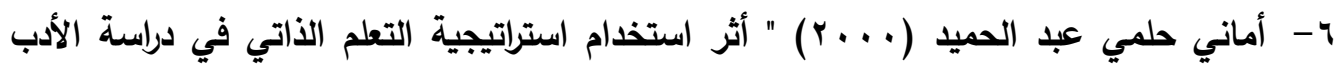

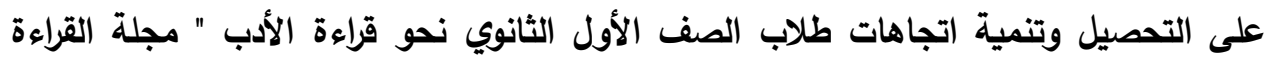

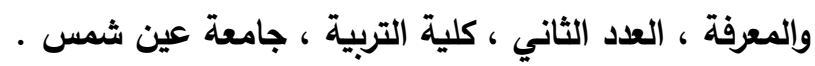

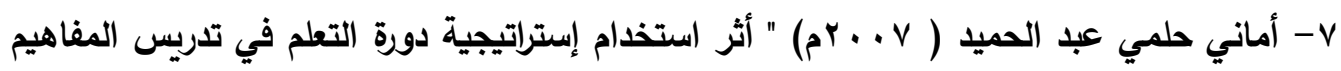

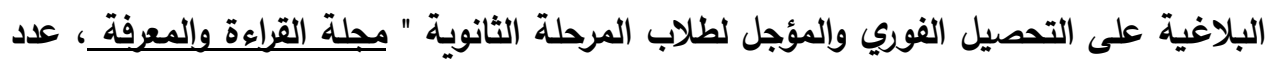

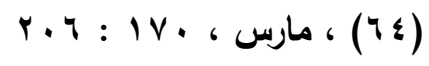

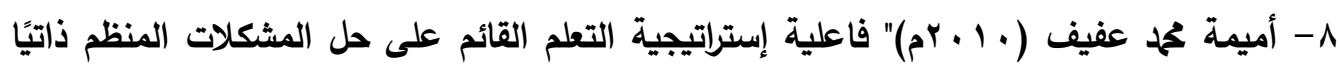

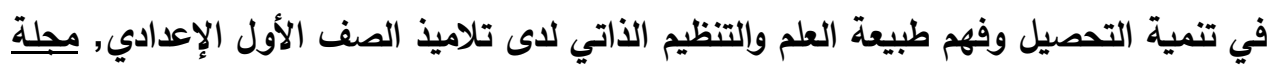

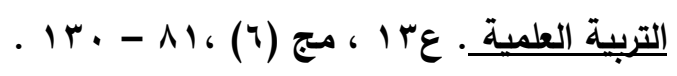

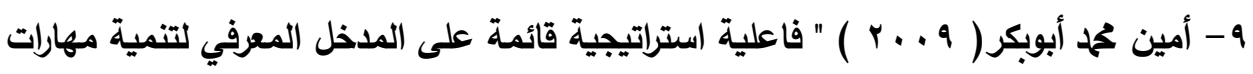

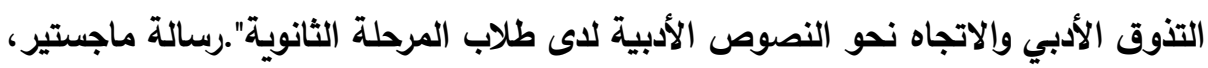
معهة الدراسات التربوية، جامعة القاهرة 


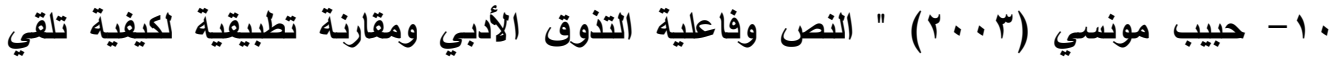

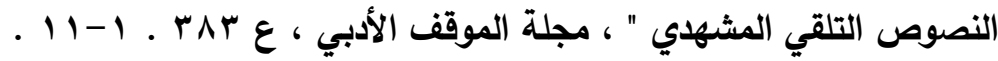

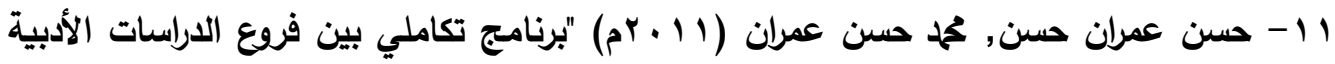
في تنمية بعض مهارات التذوق الأدبي لاى طلاب الصف الأول الثانوي وميلهر نحوها" , رحلة

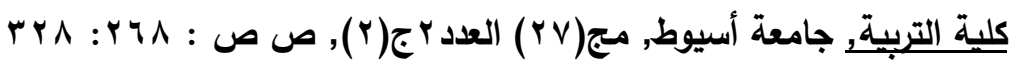

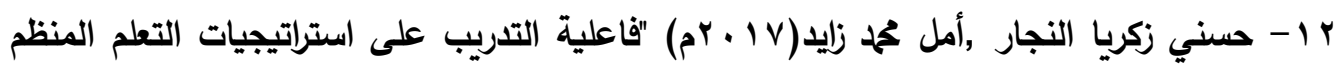
ذاتيًا في تحسين الدافعية الأكاديمية الذاتية والاتجاهات نحو لادى عينة من التلاميذ الموهوبين

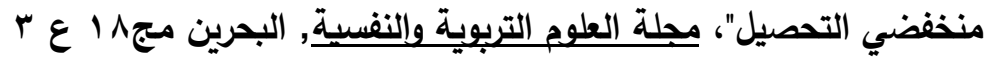

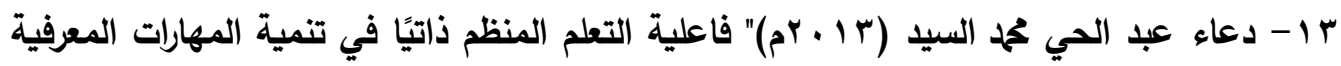
وما وراء المعرفية والحياتية من خلال تدريس العلم ولطلاب المرحلة الثانوية ", رسالة دكتوراة جامعة عين شمس.

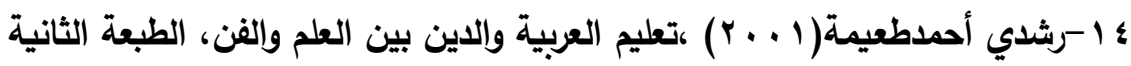

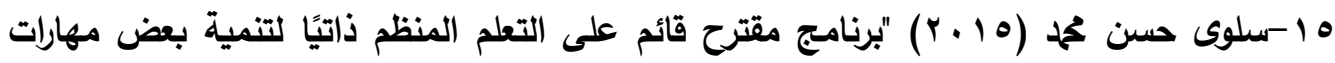

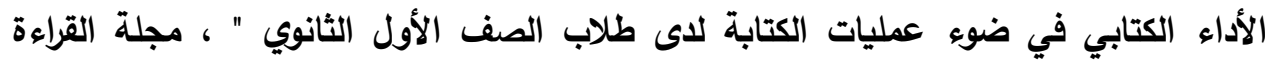

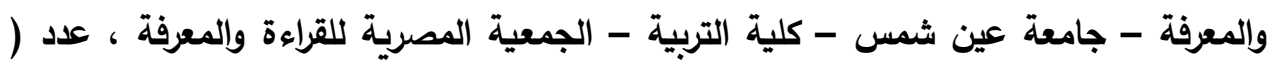

1 - سمر عبدالحليم السيد بدوي (10 ب rم) فاعلية استخدام إستراتيجية التدريس التبادلي في تنمية مهارات التذوق الأدبي في اللغة العربية لاى تلاميذ الصف الأول الإعدادي ـ مجلة جامعائه

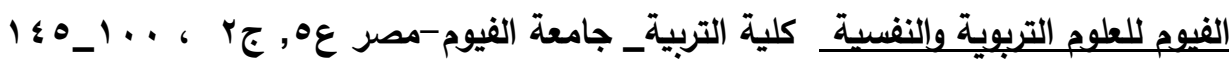

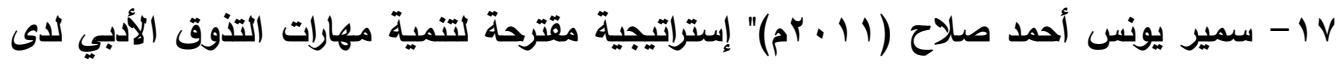

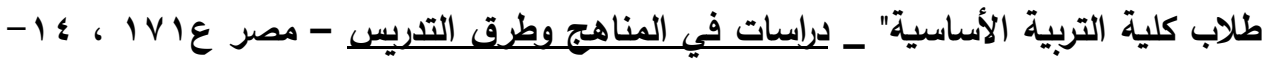
or 1 1 1-سهير السيد جمعة إسماعيل (11 + r) ، " إستراتيجيات التعلم المنظم ذاتيًا وعلاقتها بمهارات

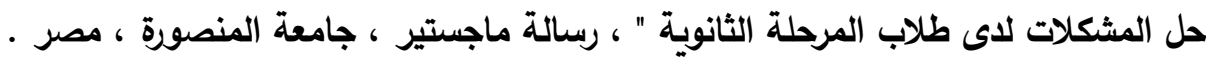

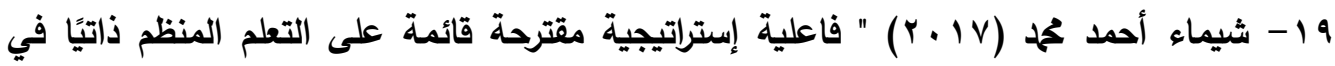
العلوم لتنمية مهارات التفكير عالي الرتبة ومهارات التنظيم الذاتي لاى طالبات التهات المرحلة

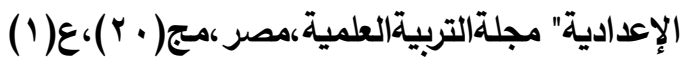




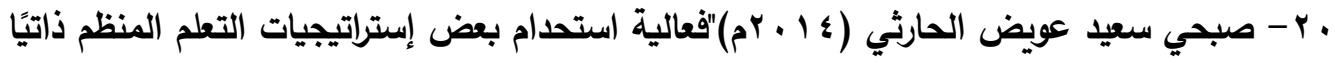

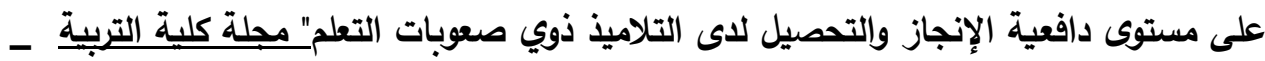

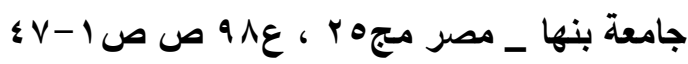

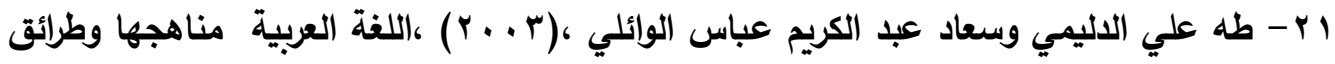
تدريسها ، بغداد ، دار الثروق للطباعة .

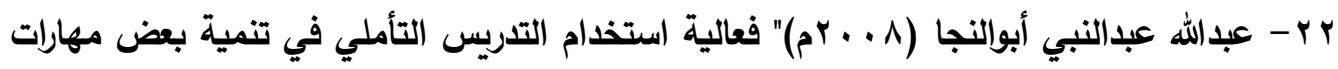

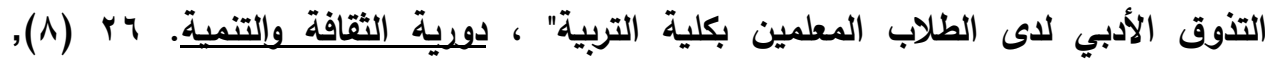
ro._iva

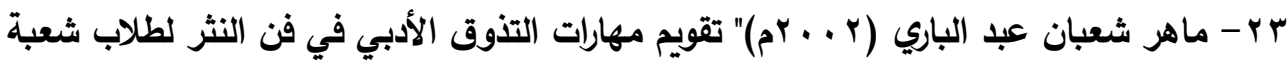

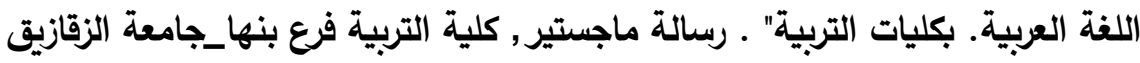

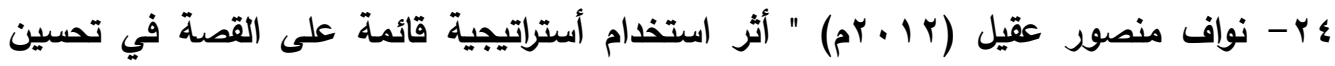
مهارات التذوق الأدبي لاى طلبة الصف العاشر الأساسي" ، رسالة ماجستير، الجامعة الأردنية،

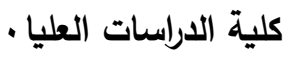

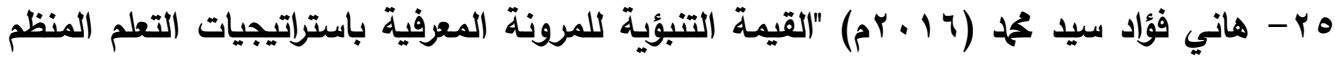
ذاتيًا لاى عينة من طلاب الجامعة بكلية التربية",جامعة حلوان, مجلة الداريسات التربوية

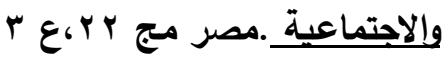

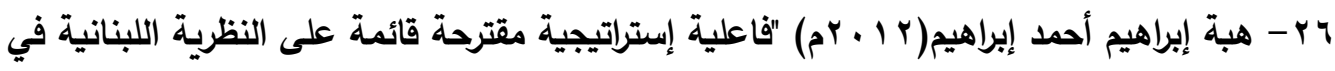

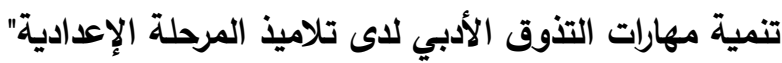

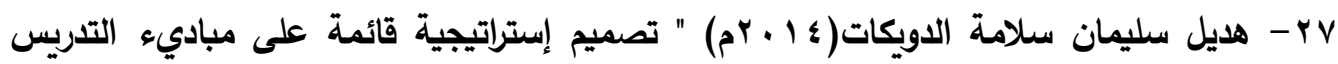

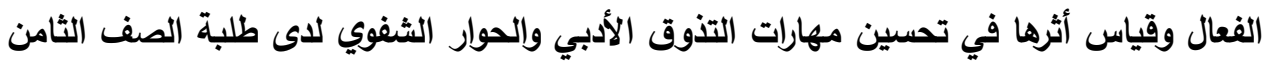

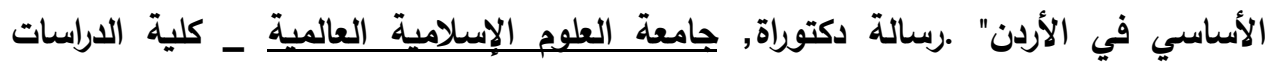
العليا_الأردن

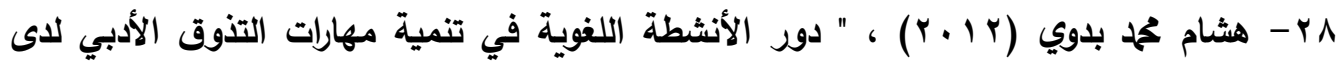

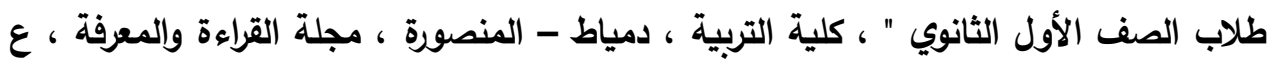

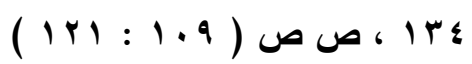

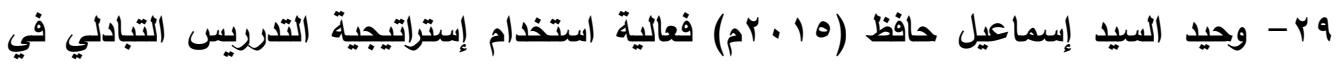
تدريس النصوص الأدبية لتنمية مهارات التذوق الأدبي ومهارات التفكير الناقد لاى طلاب

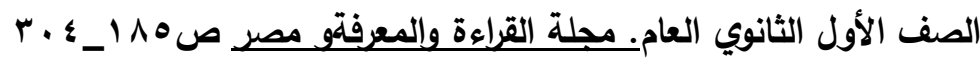

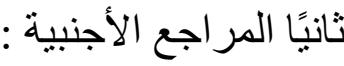


r. - Bahar,M: The relationships between pupil,s learning styies and their per formance in mini scince projects, Education science theory and practice, Vol (q) ,No. $1, r_{\ldots} . q$ $r_{\text {- }}$ Chin , C ( $\left.r \ldots \varepsilon\right)$ self - Regulated learning in science A social cognitive theory . NI : pientice . Hall , Englewood cliffs Christopher a. Walters,. ( $\uparrow \ldots \varepsilon)$ : " self - regulated learning and century competencies of educational psychology, university of Houston, electronic of research in educational psychology, $r(1)$, pp $1, r$.

$r r_{-}$- Fermin Montalvo, and Maria Torres $(r \ldots \varepsilon)$, Self-Regulated learning: current and future Directions, Electronic Journal of Research in

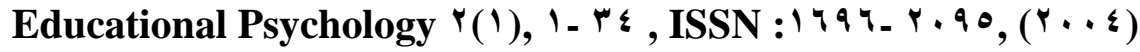

- $r$ r-Jule,S. $(r \ldots \varepsilon): "$ self regulation in college composition : no writer left behind doctor of philosophy, the bbuniversity of Arizona, Yoos David. J. Niol

$r \leqslant-$ Kosnin, A., A., M. $(r \ldots v)$ self- regulated learning and academic achievement in Malaysian and ergraduates, international education journal, $\wedge(1)$, pp. $r$ $\uparrow-r \uparrow \wedge$. $\quad r \diamond-$ Walker, J., M., $(r \ldots r)$ teacher classroom management practices as context for student self regulated learning, ph. D., Vanderbilt university .

$r$ \-Zimmerman B. $(r \ldots)$ Attaining self - regulation: Asocial cognitive . In m Bokarets.,P.R ., pentric, \& M. Zeidner,(Eds)

$r v$-Zimmerman, B. $(r \ldots r)$. Becoming a self - regulated learner : An Overview. Theory into practice, $\leqslant 1(r),(T \leqslant-V r)$. 